\title{
Anti coronavirus optimization algorithm: A socio- inspired meta-heuristic for numerical and engineering optimization problems
}

Hojjat Emami ( $\nabla$ emami@ubonab.ac.ir)

University of Bonab https://orcid.org/0000-0002-5280-4620

\section{Research Article}

Keywords: Algorithms, swarm intelligence, coronavirus, anti coronavirus optimization algorithm, numerical optimization

Posted Date: May 27th, 2021

DOl: https://doi.org/10.21203/rs.3.rs-307750/v1

License: (c) (i) This work is licensed under a Creative Commons Attribution 4.0 International License.

Read Full License 


\title{
Anti coronavirus optimization algorithm: A socio-inspired meta-heuristic for numerical and engineering optimization problems
}

\author{
Hojjat Emami
}

Received: date / Accepted: date

\begin{abstract}
This paper introduces a new swarm intelligence strategy, anti coronavirus optimization (ACVO) algorithm. This algorithm is a multi-agent strategy, in which each agent is a person that tries to stay healthy and slow down the spread of COVID-19 by observing the containment protocols. The algorithm composed of three main steps: social distancing, quarantine, and isolation. In the social distancing phase, the algorithm attempts to maintain a safe physical distance between people and limit close contacts. In the quarantine phase, the algorithm quarantines the suspected people to prevent the spread of disease. Some people who have not followed the health protocols and infected by the virus should be taken care of to get a full recovery. In the isolation phase, the algorithm cared for the infected people to recover their health. The algorithm iteratively applies these operators on the population to find the fittest and healthiest person. The proposed algorithm is evaluated on standard multi-variable single-objective optimization problems and compared with several counterpart algorithms. The results show the superiority of ACVO on most test problems compared with its counterparts.
\end{abstract}

Keywords Algorithms · swarm intelligence · coronavirus · anti coronavirus optimization algorithm $\cdot$ numerical optimization

\section{Introduction}

In recent years, optimization meta-heuristics have become increasingly one of the most interesting topics in computer science 11. A meta-heuristic algorithm is a black-box optimizer system that gets a set of problems' variables that need

\footnotetext{
* H. Emami

Department of Computer Engineering, University of Bonab, Bonab, Iran

Tel.: +98-41-37745000

Fax: +98-41-37745000

E-mail: emami@ubonab.ac.ir
} 
to be tuned and even some constraints in the form of limitations. The optimizer modifies the variables by running an updating process until reaching the optimum value of an objective function. The output is a near-optimal solution with the maximum/ minimum value of the objective function. Metaheuristics are efficient, fairly simple, flexible, derivation free, and need limited prior knowledge about problems [2]. They have drawn inspiration from a biological, physical, or social phenomenon. For example, the inspiration source of the artificial bee colony (ABC) algorithm 3 is the cooperation of honey bees in finding food sources; and the motivation of the chaotic presidential election (CPE) algorithm 4] is the people's democratic behavior in the presidential election.

In general, the main objective of all meta-heuristics is to obtain the best solutions with the minimum computational complexity in a reasonable time. Meta-heuristics should provide a proper trade-off between the exploration (diversification) and exploitation (intensification). The objective of diversification is to disperse the search agents around the solution space to efficiently explore the promising areas, while intensification ensures the algorithm searches around the current best solutions [5]. The main difference between metaheuristics is the way they adopted to achieve the best solutions. According to the search strategy and source of inspiration, meta-heuristics are classified into different groups. The most studied meta-heuristics are evolutionary and swarm intelligence algorithms. Several thorough surveys of recent metaheuristics are given in $1,6,7.7$.

Evolutionary algorithms are motivated by Darwin's evolutionary theory. They work with a collection of solutions, and generate increasingly better solutions over time using reproduction operators. The success of evolutionary algorithms is due to their ability in modeling the best features in nature, particularly biological systems evolved over millions of years. Adaptation to the environment and selection of the fittest individuals are two important characteristics of the evolutionary algorithms [4]. These algorithms can handle the problems with many variables. In the beginning, the mainstream of evolutionary algorithms was the genetic algorithm (GA) 8. In recent years, new algorithms have emerged and achieved encouraging results. The GA algorithm is inspired by natural selection and genetic variation. GA is a stochastic search approach, which works with a randomly initialized set of chromosomes. The quality of chromosomes is evaluated using a fitness function. Chromosomes are combined to generate offspring individuals through selection, crossover, and mutation. The least-fit chromosomes are replaced with offspring if they achieve better fitness. This process iterates several times until the termination conditions are met. Some distinguished evolutionary algorithms are differential evolution (DE) 9], genetic programming (GP) [10], gene expression programming (GEP) [11, covariance matrix adaptation evolution strategy (CMA-ES) [12, self-adaptive differential evolution 13] evolution strategy (ES) 14], biogeography-based optimization (BBO) 15], granular agent evolutionary (GAE) [16, cultural evolution algorithm (CEA) 17], backtracking search optimization algorithm (BSA) [18], symbiotic organisms 
search (SOS) 19], strawberry plant algorithm (SBA) 20], forest optimization algorithm (FOA) 21, and runner-root algorithm (RRA) 22.

Swarm intelligence algorithms mimics the intelligent behavior of insects or groups of animals in nature to solve real-world problems. These algorithms mainly depends on the decentralization idea in which the individuals search the solution space by extracting the useful information from a group of individuals and the environment 6]. Particle swarm optimization (PSO) 23] is a popular and oldest swarm intelligence algorithm, which widely used in different disciplines. PSO models the cooperation of a flock of migrating birds attempting to reach destination. In PSO, each search agent in solution space is called a particle. The particles explore the solution space by sharing their own local experience and the best-known experience of the others. This process iterates so that the particles move towards the best solution. Some of the well-known swarm intelligence algorithms are artificial bee colony (ABC) [3], cuckoo search algorithm (CSA) [5], ant colony optimization (ACO) 24], firefly algorithm (FA) 25, bat algorithm (BA) 26, bacterial foraging optimization (BFO) 27], teaching learning-based optimization (TLBO) [28], krill herd (KH) 29], dolphin echolocation (DEL) [30], fruit fly optimization algorithm (FOA) [31], grey wolf optimization (GWO) [32, animal migration optimization (AMO) 33 , social spider optimization ( $\mathrm{SSO}$ ) 34 , group counseling optimization (GCO) 35, lion optimization algorithm (LOA) 36], whale optimization algorithm (WOA) 2], grasshopper optimization algorithm (GOA) 37], and salp swarm algorithm (SSA) 38.

A few recent algorithms are inspired by the behavior of viruses that attack a living cell. An interesting algorithm in this area is bacterial foraging optimization (BFO) algorithm [27] that models the foraging behavior of bacteria over a landscape of nutrients. This algorithm consists of five phases that include population chemotaxis, swarming, reproduction, elimination, and dispersal. Virus optimization algorithm (VOA) [40 models the interaction between the harmless viruses and the immune system. The viruses are classified into two groups: common and strong. Common-type viruses are responsible to explore promising areas of solution space. Strong viruses reproduce at a higher rate to exploit points within target areas found by common viruses. In 40], a self-adaptive virus optimization algorithm (SaVOA) is introduced to solve the parameter initialization issue of VOA. Magnetotactic bacteria optimization algorithm (MBOA) [4] models the moment of magnetosomes and energy management and in magnetotactic bacteria. MBOA starts by calculating the magnetic field of cells. Then, the distance and interaction energy between cells is computed. Finally, moments of magnetosomes are tuned by integrating with cells to reach the minimum magnetostatic energy.

A particular algorithm may provide very well outcomes on a set of problems, but not on others. This issue is consistent with the no free lunch (NFL) theorem, which dictates that there is no algorithm best suited for solving all problems 42]. Therefore, introducing new meta-heuristics or enhancing the performance of existing ones is an active research field. In the literature, there is no research, which models the containment measures needed to control the 
transmission of coronavirus disease 2019 (COVID-19). This issue and the NFL theorem motivated our attempt to mathematically model the COVID-19 mitigation protocols, and propose a new swarm intelligence strategy, which is called anti coronavirus optimization (ACVO) algorithm. ACVO simulates the protocols recommended by the world health organization (WHO) to slow down the transmission of COVID-19 diseases and improve public health.

COVID-19 is a recently discovered infectious disease that spread throughout the world 43]. It is announced as a serious pandemic by the WHO that needs international concern 44, 45. So far, no effective vaccine or drug has been identified for COVID-19. Only some mitigation policies have been taken by the WHO and governments to COVID-19. These policies mainly include social distancing, quarantine, isolation, personal hygiene, wearing plastic screens and face masks in community, restricting the movement of people, and avoiding public gatherings in large groups [46]. The social distancing policy aims to keep a safe space between individuals. In the quarantine phase, people with suspected symptoms are separated from others and quarantined. In the isolation step, treatment is carried out for people having the disease to return them to normal conditions. These policies hopefully improve the health of people. The ACVO attempts to solve optimization problems by modeling three main mitigation policies including social distancing, quarantine, and isolation. The objective is to find the fittest and healthiest person in the population, which corresponds to a near-optimal solution to a given optimization problem.

Overall, the main contributions of this paper include:

- Introducing an anti coronavirus optimization (ACVO) algorithm inspired by the measures recommended to mitigate the spread of COVID-19.

- Investigating the ability of ACVO in solving numerical and engineering optimization problems, and compare it with counterpart algorithms. The results show that the $\mathrm{ACVO}$ achieved superior results compared with its counterparts.

The organization of the remaining parts is as follows. Section 2 presents the inspiration source and the mathematical model of the proposed ACVO. Section 3 discusses the effectiveness of the ACVO algorithm on a variety of test optimization problems. Section 4 makes some conclusions and provides some future research directions.

\section{Anti coronavirus optimization (ACVO) algorithm}

This section presents the inspiration source of the proposed ACVO algorithm and its mathematical model. Then, a simple numerical example is given to illustrate the functioning of $\mathrm{ACVO}$ on a continuous optimization problem. 


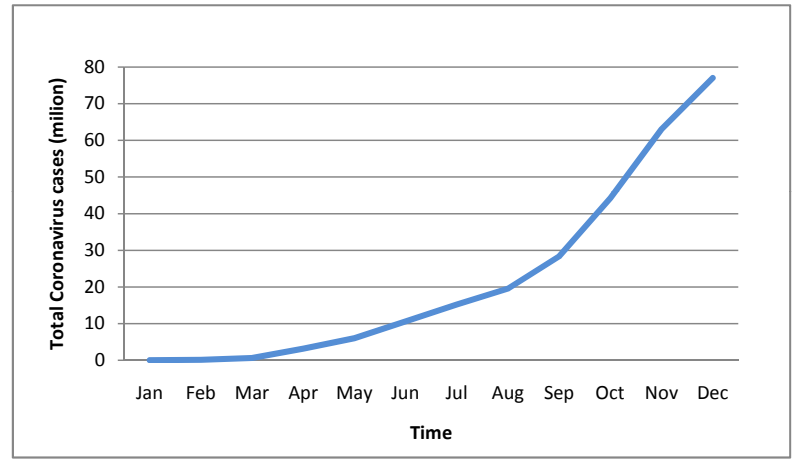

Fig. 1: The total number of confirmed cases of COVID-19 from 1 Jan. 2020 to 20 Dec. $202 q^{1}$

\subsection{Inspiration source}

COVID-19 is an emerging contagious disease caused by SARS-CoV-2 virus. It infects people of all ages, especially those with pre-existing medical conditions. According to the report published by WHO, the reproductive number $\left(R_{0}\right)$ of COVID-19 is about 2.5 [47]. It means that each infected person is infecting about 1 to 3 people on average. As shown in Fig. 1, the number of coronavirus cases is growing exponentially.

There are two main approaches to spread the coronavirus: breathing and close contact. In the former approach, the virus spreads by respiratory droplets generated when an infected person sneezes or coughs. The droplets generated in the respiratory system are large and heavy that cannot be suspended in the air for a long time, and deposit about 1 to 1.5 meters ${ }^{2}$. The transmission capacity of COVID-19 is less than 1.8 meters (6ft). In the close contacting approach, the virus can transmit from infected individuals to healthy people and infect them through close communication and physical contact. In the other form of close contact, people may be infected by touching the objects or surfaces that contain the virus, and then touching their mouth, nose or eyes.

To date, there is no effective treatment for COVID-19 disease. The WHO recommends that containment measures including social distancing, quarantine, and isolation can significantly diminish the spread of COVID-19 by removing infectious individuals from the transmission process [44, [46].

Social distancing means reducing closeness and frequency of contact between individuals to slow down the spread of a contagious disease. The safe distance recommended by the authorities varies. WHO adopted a $1 \mathrm{~m}$ (3.3ft)

1 The data for draw charts are driven from "coronavirus worldwide graphs" https:// www.worldometers.info last access 20 Dec 2020].

${ }^{2}$ Coronavirus disease (COVID-19) advice for the public: WHO, https://www.who.int/ emergencies/diseases/novel-coronavirus-2019/advice-for-public last access 20 Dec 2020] 
physical distancing policy ${ }^{3}$ China, Singapore, Lithuania, and Hong Kong recommended that $1 \mathrm{~m}(3.3 \mathrm{ft})$ is safe. The United States adopted $1.8 \mathrm{~m}(6 \mathrm{ft})$, and Canada recommended $2 \mathrm{~m}(6.6 \mathrm{ft})$ physical distancing. Because of the nature of COVID-19, if the physical distance between people is more than a safe space, the probability of spreading the virus through breathing and close contacting decreases. As the outbreak slowdowns, safe distance decreases, because other methods can be adopted to mitigate virus transmission, for example, face masks. Recent studies show that social distancing is one of the best tools to decrease the spread of the COVID-19 46, 48. Figure 2 shows the impact of social distancing on the spread of the diseases. Fig. 2(a) and (b) show the number of infected people when they reduce social exposure by 50 and $75 \%$, respectively. Without social distancing 406 people will be infected in 30 days when $R_{0}$ is 2.5 出

The quarantine is another efficient approach to curb the spread of the disease. A person should be quarantined if she/he was within 6 feet of someone who has COVID-19 for a total of 15 minutes or more, drops of sneezing or coughing of an infected individual falls on the person, had direct physical contact with the person, provided care at home to someone who is sick with COVID-19, and shared eating or drinking utensils. In the quarantine phase, the movement of people whose disease has not been definitely diagnosed but may have potentially been exposed to COVID-19 is restricted. Individuals in quarantine should separate themselves from the population, stay at home, monitor their health, and follow health directions. Health experts recommended that quarantine should last for 2 to 14 days because the time between exposure to the virus and the onset of symptoms is between 2 and 14 days. More recent estimations found that the mean incubation period was 4.2 days on average; however, it varies greatly among infected individuals [49].

The infected individuals that have a confirmed medical diagnosis are isolated from the healthy population to protect the public from exposure to the virus [50]. In isolation, infected people who are at higher risk for severe illness should be monitored and cared for. There are various forms of isolation that periodically revise according to outbreak time and environmental conditions. Some popular methods include contact isolation, respiratory isolation, reverse isolation, self-isolation, and strict isolation. Researchers are working hard to quickly find an effective treatment for COVID-19. A few methods are currently being investigated in trials as a potential therapy for COVID-19. One of the potential methods is convalescent plasma therapy [51, in which the plasma from people who have recovered transfer into the infected ones. The main principle of this method is based on the fact that people who have recovered from the disease have antibodies to the virus in their blood. It is important to notice that isolation is different from quarantine. Isolation separates infected individuals from healthy individuals, while quarantine separates and restricts

\footnotetext{
3 Social Distancing, [https://www.cdc.gov/coronavirus/2019-ncov/ prevent-getting-sick/social-distancing.html last access 20 Dec 2020]

4 https://www.visualcapitalist.com/the-math-behind-social-distancing/
} 


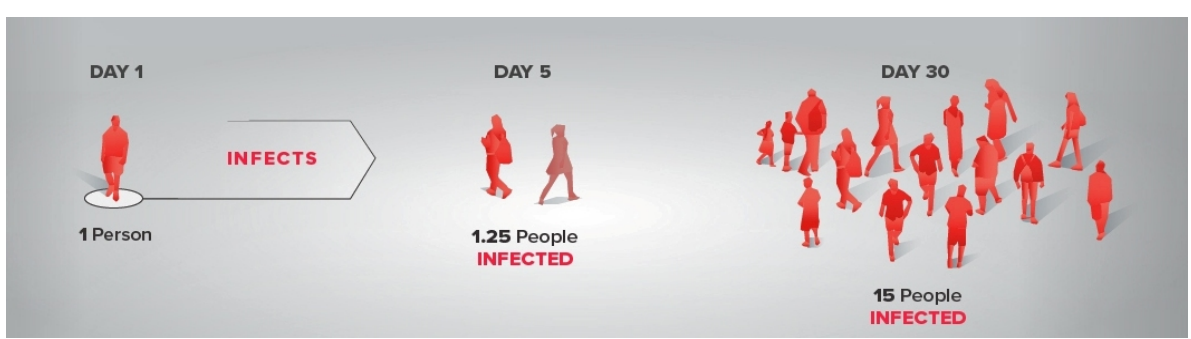

(a)

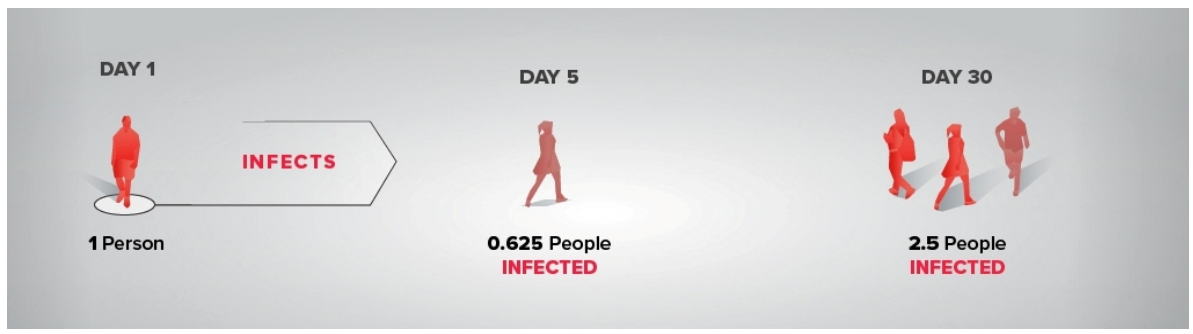

(b)

Fig. 2: The effect of social distancing on the spread of the COVID-19; (a) reducing social exposure by $50 \%$; (b) reducing social exposure by $75 \%$.

the movement of individuals who are exposed to a virus to check if they become sick. The empirical studies show that the proportion of individuals with COVID-19 that need to be isolated and admitted to the intensive care unit (ICU) was 6\% 52. The mean length of hospitalization among the recovered individuals often was in the range of 10 to 13 days 52,53 . For asymptomatic cases, discharging patients from isolation is 10 days after symptom onset, and for symptomatic cases, discharging from isolation is 10 days after symptom onset plus 3 additional days without the disease's symptoms 5

Figure 3 shows the impact of adopting the containment protocols to slow down the spread of COVID-19. Without pandemic containment measures, the virus can spread exponentially [4]. Following the mitigation measures, many governments have been able to control the coronavirus and push effective reproductive number $\left(R_{e}\right)$ to below 149 .

\subsection{Mathematical model}

Anti coronavirus optimization (ACVO) algorithm is a mathematical modeling of the containment measures developed to mitigate the spread of the COVID19. The working principle of ACVO is shown in Fig. 4. ACVO starts its work with the initialization of parameters and a population of solutions. Then, the

5 WHO, clinical management of COVID-19 (Interim Guidance) [https://www.who.int/ publications-detail/clinical-management-of-covid-19 last access 20 Dec 2020] 


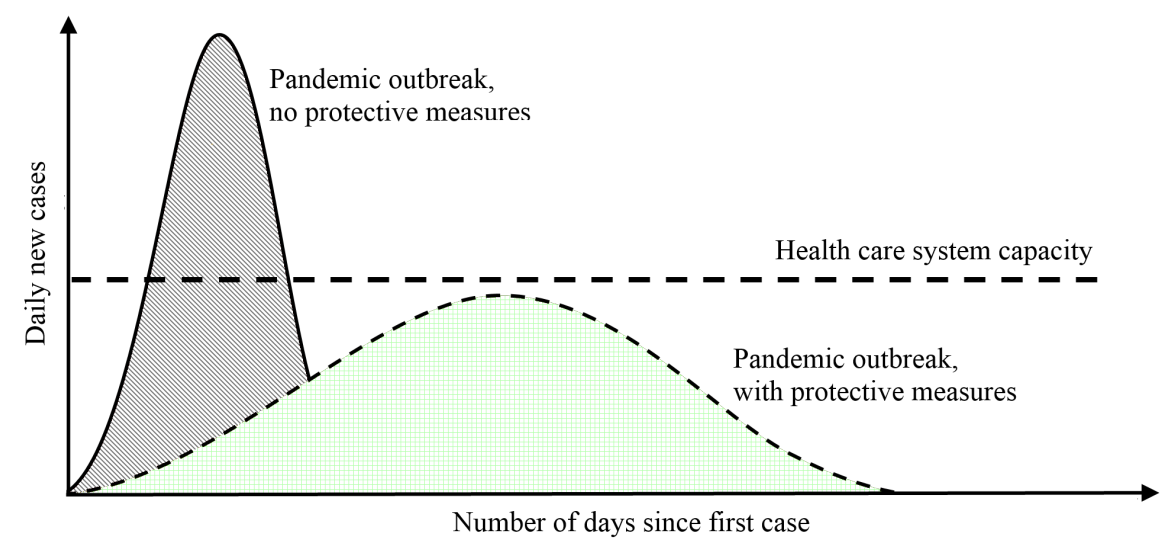

Fig. 3: Curve of COVID-19 pandemic outbreak with/ without protective measures

population is updated using three operators: social distancing, quarantine, and isolation. If termination conditions are met, the algorithm terminates, and reports the best solution; otherwise continues the population updating process. In modeling the algorithm, the following assumptions are considered:

- The basis of this algorithm is to keep all members of society healthy, recover infected people and improve their health.

- There is no concept of death in this algorithm. No one dies in this algorithm.

- It is assumed that everyone will be healthy at the end of the pandemic.

- Most of the parameters are configured according to the values recommended by WHO and other organizations involved in disease control. 


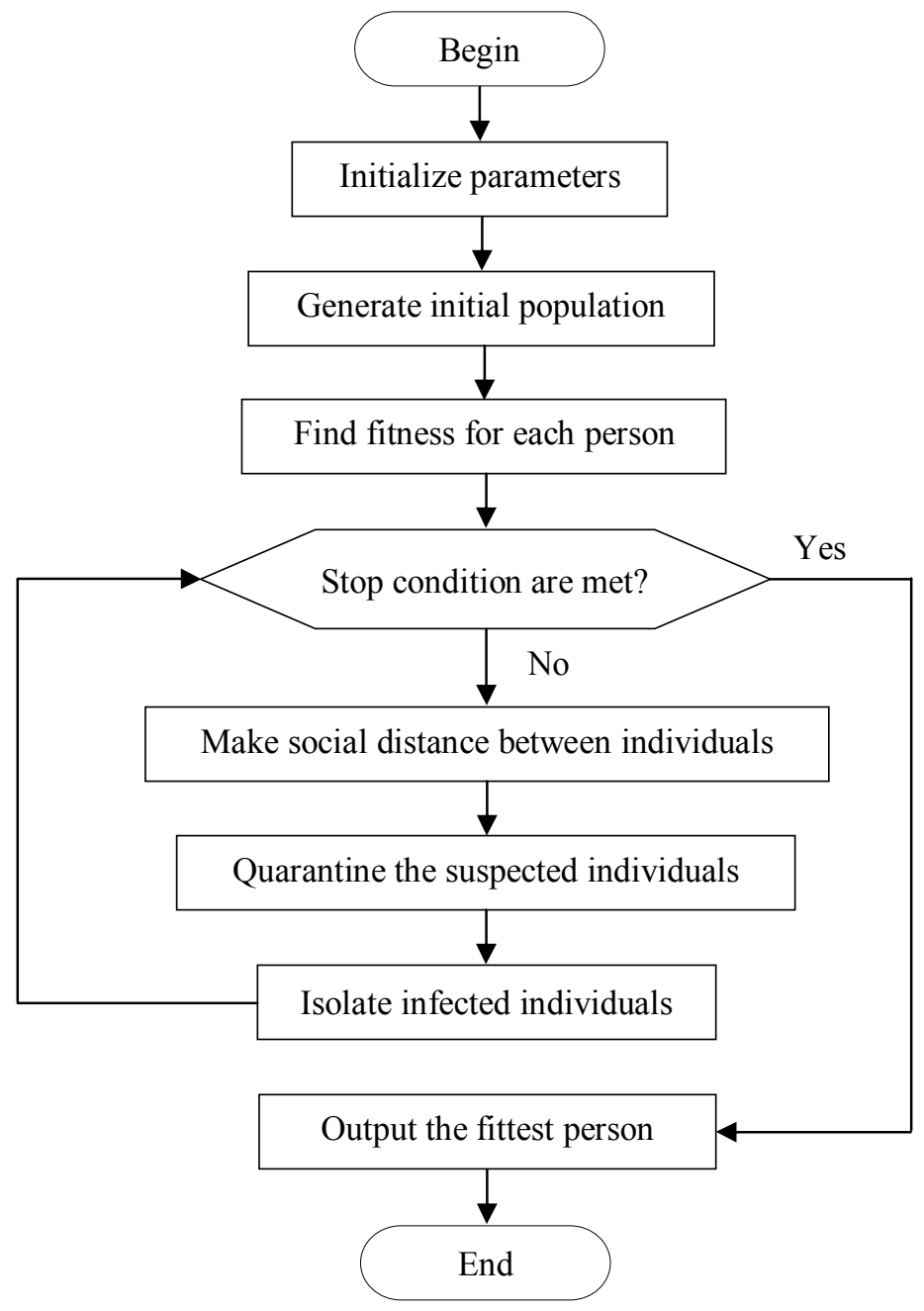

Fig. 4: Flowchart of the ACVO algorithm

\subsubsection{Population initialization}

The ACVO in each generation works with a randomly distributed population $P$, defined as follows:

$$
P=\left[P_{1}, P_{2}, \ldots, P_{N}\right]
$$

Each solution $P_{i} \in P$ in the population is called a person, which shows a point in a multidimensional space. It is encoded as a set of real-valued variables and an integer variable indicating the health status of the person.

$$
P_{i}=\left[p_{i 1}, p_{i 2}, \ldots, p_{i D}, s\right]
$$


where $p_{i j}$ consists of a possible value for $j$ th variable, and $s$ is the health status of the person that is defined as

$$
s=\left\{\begin{array}{l}
1 \quad \text { if } P_{i} \text { is healthy } \\
0 \quad \text { if } P_{i} \text { is in quarantine } \\
-1 \text { if } P_{i} \text { is in isolation }
\end{array}\right.
$$

each variable $p_{i j}$ is initialized as follows:

$$
p_{i j}=\left(p_{\max j}-p_{\min j}\right) \times r+p_{\min j}
$$

where $r \in[0,1]$ is a uniformly distributed random number, $p_{\min j}$ and $p_{\max j}$ are lower and upper bounds of $P_{i}$ in $j$ th dimension, respectively.

The individuals pass to a fitness function $f$ to assess their quality. In ACVO, it is assumed that individuals' health is proportionate to their fitness. The fitness function assigns higher fitness to healthy individuals and less fitness to weak and infected individuals.

\subsubsection{Social distancing}

This operator simulates the social distancing policy. It is obvious that not all people engage in social distancing at any given time, but only a proportion of the population follows this policy. As the disease spreads, the importance of social distancing becomes more apparent and people are forced to be more observant. To mathematically model this issue, at each iteration, $m$ number of people are selected to engage in social distancing to decrease the inter-personal contacts. The position of each selected person $P_{i}$ updates as follows:

$$
P_{i}^{t+1}=P_{i}^{t}+\Delta_{1}^{t}+\Delta_{2}^{t}
$$

where $P_{i}^{t}$ denotes the position of $i$ th person, and $t$ is the current iteration. $\Delta_{1}$ controls the local distancing between $P_{i}$ and any other individual in its vicinity. $\Delta_{2}$ controls the global distancing between $P_{i}$ and the best individual $P^{*}$, which guides $P_{i}$ into a promising position outside the current area. The objective of $\Delta_{1}$ and $\Delta_{2}$ is to move the individual $P_{i}$ into a promising area in solution space. $\Delta_{1}$ is defined as follows:

$$
\Delta_{1}^{t}=\alpha_{i j}^{t} \times s d_{i j}^{t} \times U(-1,1)
$$

where $U(-1,+1)$ is a uniform random number generator that generates +1 or $-1 . s d_{i j}^{t}$ shows the minimum physical distance that $P_{i}$ and each other individual $P_{j}$ in the population should be observed to prevent the infection. $s d_{i j}^{t}$ is defined as

$$
s d_{i j}^{t}=\left\{\begin{array}{ll}
\Delta-d_{i j}^{t} & \text { if }\left(d_{i j}^{t}<\Delta\right) \\
d_{i j}^{t} & \text { if }\left(d_{i j}^{t} \geq \Delta\right)
\end{array} \quad \text { where } \quad d_{i j}^{t}=\left\|P_{i}^{t}-P_{j}^{t}\right\|\right.
$$

$d_{i j}^{t}$ indicates the current distance between $P_{i}$ and $P_{j} . \Delta$ is the pre-defined safe physical distance between people at iteration $t$ according to the mitigation 
protocols. Since the safe physical distance may differ in various conditions and from time to time, $\Delta$ can be customized according to the epidemic conditions. $\alpha_{i j}^{t}$ is the infection effect of person $P_{j}$ on $P_{i}$, defined as

$$
\alpha_{i j}^{t}=e^{-\left(\frac{d_{i j}^{t}}{\Delta}\right)}
$$

The larger $\alpha_{i j}^{t}$ is, the stronger the infection imposed on the individual $P_{i}$. As the algorithm proceeds, the physical distance between individuals increases, hence, the disease transmission between individuals decreases, and the outbreak slowdowns.

$\Delta_{2}^{t}$ is defined as follows:

$$
\Delta_{2}^{t}=\beta_{i j}^{t} \times V \times\left(P^{*}-P_{i}^{t}\right)
$$

where $\beta_{i j}^{t}$ is the infection effect of $P^{*}$ on $P_{i} . V$ is the step size, which adjusts the amount of movement of $P_{i}$ towards $P^{*}$ with different distance steps. $P^{*}$ is the best solution found until current iteration. $V$ is computed by Levy distribution 56] as follows:

$$
V \sim \frac{\lambda \Gamma(\lambda) \sin (\pi \lambda / 2)}{\pi} \frac{1}{s^{1+\lambda}}, \quad s \gg s_{0}>0, \quad s_{0}=0.1
$$

$\Gamma(\lambda)$ denotes the standard gamma distribution, where $\lambda$ is set to be 1.5 . The variable $s$ is defined as

$$
s=\frac{U}{|V|^{1 / \lambda}}, \quad U \sim N\left(0, \delta^{2}\right), \quad V \sim N(0,1)
$$

where $U$ and $V$ are Gaussian distributions, $N\left(0, \delta^{2}\right)$ indicates the normal distribution with mean 0 and variance $\delta^{2}$, and $N(0,1)$ is the standard normal distribution.

$$
\beta_{i j}^{t}=e^{-\left(\frac{\left\|P^{*}-P_{i}^{t}\right\|}{\Delta}\right)}
$$

The idea behind Eq. (9) is to direct the other individuals towards the best individual $P^{*}$, which is the leader in following the virus mitigation protocols.

\subsubsection{Quarantine}

The quarantine operator simulates the actions that each suspected person with COVID-19 should take during the quarantine phase. In the ACVO, the people suspected of having the disease are those who obtain low fitness during the optimization process. To determine the suspected people, first, the individuals are sorted based on their fitness in ascending order. Here, it is assumed that the problem is maximization, and the fitness value indicates the health condition of a person. In minimization problems, the individuals will be sorted in descending order, because the infected ones will have high cost and low fitness. Then, the $q$ number of the weakest individuals are selected to form 
the quarantine list $Q=\left\{P_{1}, P_{2}, \ldots, P_{q}\right\}$. This list is composed of suspected individuals that should be quarantined to determine if they were infected or not. The parameter $q$ at each iteration $t$ is computed as

$$
q^{t}=\left\lceil\left(\left(1-\left(1-\left(\lambda^{t}\right)^{2}\right) m^{t}\right) R_{0}\right\rceil\right.
$$

where $q^{t}$ is the effective reproductive number at iteration $t$. It counts the number of suspected individuals that may have potentially been exposed to diseases. $m^{t}$ is the fraction of the population that takes part in social distancing to mitigate their interpersonal contacts to a fraction of $\lambda$ of normal conditions. $R_{0}$ is the basic reproductive number. In a population where everyone is equally susceptible to a disease, $R_{0}$ indicates the average number of secondary infected cases caused by one primary infected person. At the time of writing this paper, the $R_{0}$ of the COVID -19 is estimated to be 1.4-2.5 [46. If we assume $R_{0}$ to be 2.5 , and $m=25 \%$ of the population take part in social distancing to decrease their interpersonal relations to $\lambda=50 \%$ of normal contacts, then $q^{t} \approx 3$. Under this condition, a single infected person would generate an average of 3 new secondary infected cases. If $q>1$, the number of infected individuals will increase, and where $q<1$ the number of infected cases decreases. To successfully eliminate COVID-19 from the population, $q$ needs to be less than 1. To realize this goal, the algorithm should increase the value of $m$, and simultaneously decrease $\lambda$ as it proceeds. The following equations are proposed to control the values of $m$ and $\lambda$ :

$$
\begin{gathered}
\lambda^{t}=1-\frac{t}{T} \\
m^{t}=\frac{t}{T}
\end{gathered}
$$

where $T$ is the maximum number of generations.

The algorithm randomly selects $k_{1}$ variables from each suspected person $P_{i} \in Q$, and updates them by Eq. (17). To select the variables, the algorithm takes as input the solution dimension $D$ and $k_{1}$, then generates $k_{1}$ pseudorandom integers, $\left\{r_{1}, r_{2}, \ldots, r_{k_{1}}\right\}$ using the discrete uniform distribution on the interval $[1, D]$. Each random number $r_{j}$ shows the position of a variable $p_{i j} \in P_{i}$ that to be selected and updated. $k_{1}$ is calculated as

$$
k_{1}=\left\lceil r_{1} \times D\right\rceil
$$

where $r_{1}$ is a small uniform random number. The selected variables are updated as follows:

$$
p_{i k}^{t+1}=p_{i k}^{t}+U(-1,+1) \times \text { rand }
$$

rand is a random number in the range $[0,1]$. The suspected individuals should quarantine for $q_{d}$ days and their variables are updated with Eq. 177). After the end of the quarantine period, if the fitness of $P_{i}$ is greater than or equal to its fitness on the first day of quarantine, then $P_{i}$ is recognized 
as healthy and returns to the population, otherwise it must be isolated and hospitalized. The following equation formulates this issue:

$$
\left\{\begin{array}{c}
P^{t+1}=\left\{P^{t}\right\} \cup\left\{P_{i}^{t}\right\} \text { if }\left(f_{i}^{q_{e}} \geq f_{i}^{q_{s}}\right) \\
I^{t+1}=\left\{I^{t}\right\} \cup\left\{P_{i}^{t}\right\} \quad \text { else }
\end{array}\right.
$$

where $P$ is the population, and $I$ is the isolation list. $f_{i}^{q_{s}}$ and $f_{i}^{q_{e}}$ show the fitness of individual $P_{i}$ at the first and last day of quarantine, respectively. $q_{s}$ and $q_{e}$ are the iteration number at the first and last day of the quarantine, respectively. $q_{e}$ is equal to $q_{s}+q_{d}$, where $q_{d}$ is the duration of quarantine. $q_{d}$ is initialized according to the WHO recommendations.

\subsubsection{Isolation}

The isolation operator simulates the health measures taken to treat infected individuals and get back them to normal conditions. In the current version of ACVO, the convalescent plasma therapy is modeled to treat infected individuals. In this way, some characteristics of the fittest healthy person are injected into the infected individuals. To simulate this process, the algorithm randomly selects $k_{2}$ variables from each isolated person $P_{i} \in I$, and updates them by Eq. (20). $k_{2}$ is computed as

$$
k_{2}=\left\lceil r_{2} \times D\right\rceil
$$

where $r_{2}$ is a uniform random number, regenerated every iteration. Since the variable $r_{2}$ regenerates at every iteration and varies for each solution $P_{i}$, the number of variables selected from each solution is different from other solutions. The selected variables are updated using the following equation:

$$
p_{i j}^{t+1}=\frac{1}{2}\left(p_{i j}^{t}+\left(\gamma \times p_{j}^{* t}\right)\right)
$$

where $p_{i j}^{t}$ shows the $j$ th element of $P_{i}$ at iteration $t, p_{j}^{* t}$ shows the $j$ th element of fittest individual $P^{*} \cdot \gamma$ is a scaling factor, which measures the improvement effect of $p_{j}^{* t}$ on $p_{i j}^{t}$. Eq. 20 simply simulates the convalescent plasma therapy by combining the variables of the best-fit individual $P^{*}$ with the corresponding components of the infected person $P_{i}$. In the early days of hospitalization, more care is taken, while in the last days, drugs and care are reduced. Therefore, it makes sense to reduce the coefficient $\gamma$ over isolation time. $\gamma$ is defined as follows:

$$
\gamma^{v}=1-\frac{v}{h_{d}}
$$

$v$ ranges from 1 to $h_{d}$, where $h_{d}$ is the maximum duration of isolation. The infected individuals are isolated for $K_{2}$ days. After the end of the hospitalization period, if the person's fitness is greater than or equal to his/her fitness on the first day of isolation, the person is recognized as healthy and returns to the population; otherwise, care and hospitalization should continue. The following equation formulates this issue: 


$$
\left\{\begin{aligned}
P^{t+1} & =\left\{P^{t}\right\} \cup\left\{P_{i}^{t}\right\} \text { if }\left(f_{i}^{h_{e}} \geq f_{i}^{q_{s}}\right) \\
I^{t+1} & =\left\{I^{t}\right\} \cup\left\{P_{i}^{t}\right\} \quad \text { else }
\end{aligned}\right.
$$

$f_{i}^{h_{e}}$ is the fitness of individual $P_{i}$ at the last day of hospitalization, and $f_{i}^{q_{s}}$ is the fitness of $P_{i}$ at the first day of quarantine. $h_{e}$ is the iteration number at the last day of the isolation. $h_{e}$ is equal to $h_{s}+h_{d}$, where $h_{s}$ is the iteration number at the first day of the isolation. $h_{d}$ is configured according to the WHO recommendations.

\subsubsection{Selecting the best solution}

Until termination conditions are not met three operators- social distancing, quarantine and isolation- are applied to update the population. Finally, an individual that obtained the best fitness will introduce as the optimal solution for the problem. The algorithm terminates when the status of all individuals to be healthy $(s=1)$, or the maximum number of function evaluations (NFEs) reaches to a predefined value.

Algorithm 1 summarizes the pseudo code of the ACVO. In Section 3 , we will present intuitive reasoning of why the ACVO algorithm is an efficient optimization algorithm.

\subsection{A numerical example}

The following numerical problem is used to illustrate how the ACVO algorithm updates the population and finds optimal solutions.

$$
\begin{aligned}
& f(\mathbf{x})=f\left(x_{1}, x_{2}\right)=\left(4-2.1 x_{1}^{2}+\frac{x_{1}^{4}}{3}\right) x_{1}^{2}+x_{1} x_{2}+\left(-4+4 x_{2}^{2}\right) x_{2}^{2} \quad-5 \leq \\
& x_{1}, x_{2} \leq 5
\end{aligned}
$$

This function is called six-hump camel. Its global minimum is -1.0316 at $\left(x_{1}, x_{2}\right)=(0.0898,-0.7126)$. Fig. 5 (a) shows the 3D plot of this function. Figure 5 (b)-(f) show the population updating mechanism of ACVO in five generations on test function. Without loss of generality, for simplicity and space saving, it is assumed that individuals reduced their close contact to $\lambda=0.75$, and the quarantine and isolation period are set to be 2 and 3 days, respectively. As shown in Fig. 5 . ACVO improves the individuals at each iteration by social distancing, quarantine, and isolation operators. Individuals are gradually moving towards the optimal solution. 


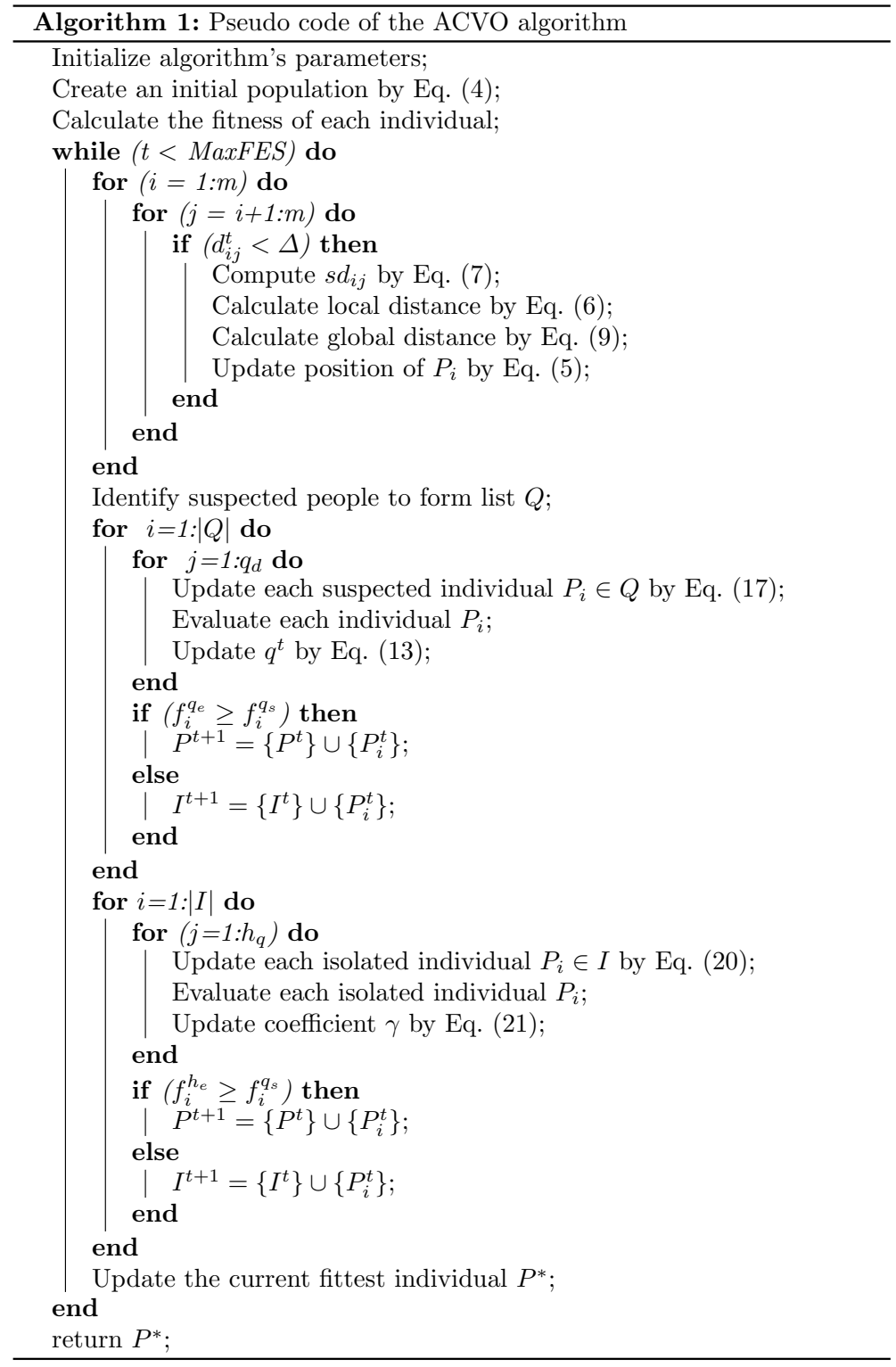

\section{Experiment and analysis}

To evaluate the performance of the proposed ACVO algorithm, seven wellestablished optimization algorithms are adopted to make a comparison. These algorithms are WOA [2], ABC [3, SADE [13], PSOGSA [54], TLBO 55], HHO [57, and HGSA [58. The ABC, TLBO, WOA, and HHO are popular swarm intelligence algorithms, and the SADE and HGSA are evolutionary 


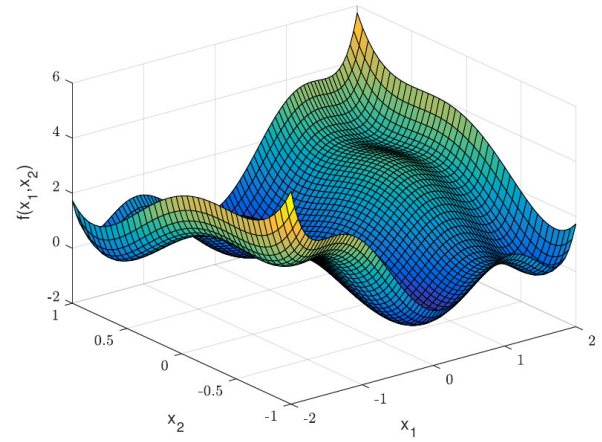

(a)

\begin{tabular}{|c|c|c|c|c|c|c|c|c|c|}
\hline$t$ & $x_{1}$ & $x_{2}$ & $f(x)$ & $s$ & $t$ & $x_{1}$ & $x_{2}$ & $f(x)$ & $s$ \\
\hline \multirow{8}{*}{ Initial } & $-1.45 \mathrm{E}+00$ & $1.91 \mathrm{E}+00$ & $3.76 \mathrm{E}+01$ & 1 & \multirow{8}{*}{1} & $-1.14 \mathrm{E}+00$ & $1.11 \mathrm{E}+00$ & $2.28 \mathrm{E}+00$ & 1 \\
\hline & $-2.84 \mathrm{E}+00$ & $1.09 \mathrm{E}+00$ & $6.82 \mathrm{E}+01$ & 1 & & $-2.34 \mathrm{E}+00$ & $-1.59 \mathrm{E}-02$ & $1.39 \mathrm{E}+01$ & 1 \\
\hline & $-2.86 \mathrm{E}+00$ & $-3.15 \mathrm{E}-01$ & $7.56 \mathrm{E}+01$ & 1 & & $-1.48 \mathrm{E}+00$ & $1.69 \mathrm{E}+00$ & $2.08 \mathrm{E}+01$ & 1 \\
\hline & $-2.00 \mathrm{E}+00$ & $-3.13 \mathrm{E}+00$ & $3.53 \mathrm{E}+02$ & 1 & & $-1.45 \mathrm{E}+00$ & $1.91 \mathrm{E}+00$ & $3.76 \mathrm{E}+01$ & 1 \\
\hline & $-3.71 \mathrm{E}+00$ & $3.23 \mathrm{E}+00$ & $9.06 \mathrm{E}+02$ & 1 & & $-2.84 \mathrm{E}+00$ & $1.09 \mathrm{E}+00$ & $6.82 \mathrm{E}+01$ & 1 \\
\hline & $-3.17 \mathrm{E}+00$ & $-3.81 \mathrm{E}+00$ & $9.65 \mathrm{E}+02$ & 1 & & $-2.86 \mathrm{E}+00$ & $-3.15 \mathrm{E}-01$ & $7.56 \mathrm{E}+01$ & 1 \\
\hline & 6.41E-01 & $4.22 \mathrm{E}+00$ & $1.20 \mathrm{E}+03$ & 1 & & $-2.10 \mathrm{E}+00$ & $2.86 \mathrm{E}+00$ & $3.47 \mathrm{E}+02$ & 0 \\
\hline & $3.64 \mathrm{E}+00$ & $4.33 \mathrm{E}+00$ & $1.80 \mathrm{E}+03$ & 1 & & $-2.00 \mathrm{E}+00$ & $4.11 \mathrm{E}+00$ & $3.53 E+02$ & 0 \\
\hline
\end{tabular}

(b)

(c)

\begin{tabular}{|c|c|c|c|c|c|c|c|c|c|}
\hline$t$ & $x_{1}$ & $x_{2}$ & $f(x)$ & $s$ & $t$ & $x_{1}$ & $x_{2}$ & $f(x)$ & $S$ \\
\hline \multirow{8}{*}{2} & $-1.13 \mathrm{E}+00$ & $9.81 \mathrm{E}-01$ & $1.12 \mathrm{E}+00$ & 1 & \multirow{8}{*}{3} & $-8.07 \mathrm{E}-01$ & $8.31 \mathrm{E}-01$ & $2.80 \mathrm{E}-01$ & 1 \\
\hline & $-1.14 \mathrm{E}+00$ & $1.11 \mathrm{E}+00$ & $2.28 \mathrm{E}+00$ & 1 & & $-1.13 \mathrm{E}+00$ & $9.81 \mathrm{E}-01$ & $1.12 \mathrm{E}+00$ & 1 \\
\hline & $-1.83 E+00$ & $-2.14 \mathrm{E}-01$ & $2.58 \mathrm{E}+00$ & 1 & & $-2.00 \mathrm{E}+00$ & $-2.39 E+00$ & $1.16 \mathrm{E}+02$ & 1 \\
\hline & $-2.34 \mathrm{E}+00$ & $-1.59 \mathrm{E}-02$ & $1.39 \mathrm{E}+01$ & 1 & & $2.76 \mathrm{E}+00$ & $2.86 \mathrm{E}+00$ & $2.98 \mathrm{E}+02$ & 1 \\
\hline & $-1.40 \mathrm{E}+00$ & $-8.03 \mathrm{E}-01$ & $1.76 \mathrm{E}+01$ & 0 & & $-1.31 \mathrm{E}+00$ & $3.81 \mathrm{E}-01$ & $1.36 \mathrm{E}+00$ & 0 \\
\hline & $-1.48 \mathrm{E}+00$ & $1.62 \mathrm{E}+00$ & $2.08 \mathrm{E}+01$ & 0 & & $3.50 \mathrm{E}+00$ & $-8.03 E-01$ & $1.76 \mathrm{E}+01$ & 0 \\
\hline & $2.76 \mathrm{E}+00$ & $2.86 \mathrm{E}+00$ & $3.47 \mathrm{E}+02$ & 0 & & $-1.48 \mathrm{E}+00$ & $-2.15 \mathrm{E}+00$ & $2.08 \mathrm{E}+01$ & 0 \\
\hline & $-2.00 \mathrm{E}+00$ & $-2.39 \mathrm{E}+00$ & $3.53 E+02$ & 0 & & $-1.14 \mathrm{E}+00$ & $-7.47 \mathrm{E}-01$ & $2.28 \mathrm{E}+00$ & 0 \\
\hline
\end{tabular}

(d)

(e)

\begin{tabular}{|c|c|c|c|c|c|c|c|c|c|}
\hline$t$ & $x_{1}$ & $x_{2}$ & $f(x)$ & $S$ & $t$ & $x_{I}$ & $x_{2}$ & $f(x)$ & $s$ \\
\hline \multirow{8}{*}{4} & $-7.35 \mathrm{E}-01$ & $7.69 \mathrm{E}-01$ & $6.91 \mathrm{E}-02$ & 1 & \multirow{8}{*}{5} & $3.40 \mathrm{E}-01$ & $-7.47 \mathrm{E}-01$ & $-8.06 \mathrm{E}-01$ & 1 \\
\hline & $-8.07 \mathrm{E}-01$ & $8.31 \mathrm{E}-01$ & $2.80 \mathrm{E}-01$ & 1 & & $-7.35 \mathrm{E}-01$ & $7.69 \mathrm{E}-01$ & $6.91 \mathrm{E}-02$ & 1 \\
\hline & $-1.13 \mathrm{E}+00$ & $-2.66 \mathrm{E}+00$ & $1.12 \mathrm{E}+00$ & 0 & & $-8.07 \mathrm{E}-01$ & $8.31 \mathrm{E}-01$ & $2.80 \mathrm{E}-01$ & 1 \\
\hline & $-1.31 \mathrm{E}+00$ & $-2.90 \mathrm{E}+00$ & $1.36 \mathrm{E}+00$ & 0 & & $-1.63 \mathrm{E}+00$ & $-1.34 \mathrm{E}+00$ & $9.91 \mathrm{E}+00$ & 1 \\
\hline & $3.40 \mathrm{E}-01$ & $-7.47 \mathrm{E}-01$ & $2.28 \mathrm{E}+00$ & 0 & & $-1.13 \mathrm{E}+00$ & $4.64 \mathrm{E}+00$ & $1.12 \mathrm{E}+00$ & 0 \\
\hline & $-1.29 \mathrm{E}+00$ & $6.08 \mathrm{E}-01$ & $2.56 \mathrm{E}+00$ & 0 & & $-1.29 \mathrm{E}+00$ & $2.86 \mathrm{E}+00$ & $2.56 \mathrm{E}+00$ & 0 \\
\hline & $-1.63 \mathrm{E}+00$ & $-2.15 E+00$ & $7.24 \mathrm{E}+01$ & -1 & & $-1.44 \mathrm{E}+00$ & $-2.90 \mathrm{E}+00$ & $2.57 \mathrm{E}+02$ & -1 \\
\hline & $3.50 \mathrm{E}+00$ & $-6.47 \mathrm{E}-01$ & $3.47 \mathrm{E}+02$ & -1 & & $3.50 \mathrm{E}+00$ & $-3.37 \mathrm{E}-01$ & $3.49 \mathrm{E}+02$ & -1 \\
\hline
\end{tabular}

(f)

(g)

Fig. 5: A numerical example to illustrate the functioning of ACVO 
Table 1: Characteristics of the IEEE-CEC 2018 test suite

\begin{tabular}{llll}
\hline No. & Problem & Type & $F_{\min }$ \\
\hline$f_{1}$ & Shifted and Rotated Bent Cigar Function & $\mathrm{U}$ & 100 \\
$f_{2}$ & Shifted and Rotated Sum of Different Power Function & $\mathrm{U}$ & 200 \\
$f_{3}$ & Shifted and Rotated Zakharov Function & $\mathrm{U}$ & 300 \\
$f_{4}$ & Shifted and Rotated Rosenbrock's Function & $\mathrm{M}$ & 400 \\
$f_{5}$ & Shifted and Rotated Rastrigin's Function & $\mathrm{M}$ & 500 \\
$f_{6}$ & Shifted and Rotated Expanded Scaffer's F6 Function & $\mathrm{M}$ & 600 \\
$f_{7}$ & Shifted and Rotated Lunacek Bi_Rastrigin Function & $\mathrm{M}$ & 700 \\
$f_{8}$ & Shifted and Rotated Non-Continuous Rastrigin's Function & $\mathrm{M}$ & 800 \\
$f_{9}$ & Shifted and Rotated Levy Function & $\mathrm{M}$ & 900 \\
$f_{10}$ & Shifted and Rotated Schwefel's Function & $\mathrm{M}$ & 1000 \\
$f_{11}$ & Hybrid Function 1 $(K=3)^{*}$ & $\mathrm{H}$ & 1100 \\
$f_{12}$ & Hybrid Function 2 $(K=3)$ & $\mathrm{H}$ & 1200 \\
$f_{13}$ & Hybrid Function 3 $(K=3)$ & $\mathrm{H}$ & 1300 \\
$f_{14}$ & Hybrid Function 4 $(K=4)$ & $\mathrm{H}$ & 1400 \\
$f_{15}$ & Hybrid Function 5 $(K=4)$ & $\mathrm{H}$ & 1500 \\
$f_{16}$ & Hybrid Function 6 $(K=4)$ & $\mathrm{H}$ & 1600 \\
$f_{17}$ & Hybrid Function 6 $(K=5)$ & $\mathrm{H}$ & 1700 \\
$f_{18}$ & Hybrid Function 6 $(K=5)$ & $\mathrm{H}$ & 1800 \\
$f_{19}$ & Hybrid Function 6 $(K=5)$ & $\mathrm{H}$ & 1900 \\
$f_{20}$ & Hybrid Function 6 $(K=6)$ & $\mathrm{H}$ & 2000 \\
$f_{21}$ & Composition Function $1(K=3)$ & $\mathrm{C}$ & 2100 \\
$f_{22}$ & Composition Function 2 $(K=3)$ & $\mathrm{C}$ & 2200 \\
$f_{23}$ & Composition Function 3 $(K=4)$ & $\mathrm{C}$ & 2300 \\
$f_{24}$ & Composition Function $4(K=4)$ & $\mathrm{C}$ & 2400 \\
$f_{25}$ & Composition Function $5(K=5)$ & $\mathrm{C}$ & 2500 \\
$f_{26}$ & Composition Function $6(K=5)$ & $\mathrm{C}$ & 2600 \\
$f_{27}$ & Composition Function $7(K=6)$ & $\mathrm{C}$ & 2700 \\
$f_{28}$ & Composition Function $8(K=6)$ & & 2800 \\
\hline$* K$ indicates the number of components in function $f_{i}$ & &
\end{tabular}

* $K$ indicates the number of components in function $f_{i}$

algorithms that have been introduced recently and obtained the best results on numerical optimization problems.

\subsection{Benchmark problems}

Table 1 summarizes the characteristics of test functions. The test suite contains 28 single objective minimization problems drawn from CEC2018 [59]: three unimodal $(\mathrm{U})$, seven multimodal $(\mathrm{M})$, ten hybrid $(\mathrm{H})$, and eight composition $(\mathrm{C})$ functions. These problems are more complex, difficult, and have many local optima. Therefore, they are suitable to test the algorithms' accuracy, reliability, convergence rate, and the ability to avoid the local optima. Detailed information about these problems is given in [59]. To clearly show the scalability of algorithms, the test functions with three dimensions 10, 30, and 50 are considered to assess their performance on low, medium, and large scale. The search domain for all test problems is $[-100,100]^{D}$, where $D$ indicates the dimension of test problems. In Table $1, F_{\min }$ stands for the global optimum of benchmark problem. 
Table 2: Parameter tuning of ACVO and comparison algorithms

\begin{tabular}{ll}
\hline Algorithm & Parameters \\
\hline SADE 13] & $p=0.05, C=0.1, C R=N\left(C R_{m} ; 0.1\right), F=N(0.5 ; 0.3)$ \\
ABC [3] & limit $=N \times D$ \\
PSOGSA 54$]$ & $K \in[n, 2], w_{1}(t)=0.5, w_{2}(t)=1.5, \alpha=20, G_{0}=100$ \\
HHO [57] & $\beta=1.5, E_{0} \in[-1,1]$ \\
WOA 20 & $a \in[0,2], a_{2} \in[-1,-2]$ \\
TLBO 55$]$ & $T=1,2$ \\
HGSA [58] & $K \in[n, 2], L=100, G_{0}=100, w_{1}(t)=1-t^{6} / T^{6}, w_{2}(t)=t^{6} / T^{6}$ \\
ACVO & $R_{0}=2.5, \Delta=2, q_{d}=5, h_{d}=10, r_{1}, r_{2} \in[0,0.5]$ \\
\hline
\end{tabular}

\subsection{Experimental setup}

All algorithms are implemented in Matlab language on a Laptop machine with 8GB RAM and 2.2GHz Intel(R) Core (TM) i7 CPU. Following the guidance provided in [59], the algorithms executed 30 times independently, each time with a different population to obtain statistical results for each benchmark function. The maximum number of fitness function evaluations is initialized as $10,000 \times D$, and the population size of all the algorithms is 50 . Other specific parameters of algorithms are configured following the recommended settings in the original works, and summarized in Table 2.

\subsection{Results}

Tables 3-5 respectively summarize the statistical results on 10,30 , and $50 \mathrm{D}$ functions. The results are shown in mean \pm std format, where mean is the the mean cost, and std is the standard deviation obtained in all simulation runs. In the tables, the best values obtained by the algorithms on each function is represented in boldface. Results demonstrate that ACVO obtains the best results on the most functions due to its high strength in finding the optimal solutions.

Table 6 shows the final and average ranks of the algorithms computed by the Friedman test 60 according to the mean cost values. The first rank belongs to the ACVO algorithm in all dimensions. The second rank belongs to SADE in 10 and 30D functions, and HGSA in 50D functions. The third rank belongs to $\mathrm{HHO}$, HGSA, and SADE, respectively in 10, 30, and $50 D$ functions. It can be observed that the ACVO is a competitive algorithm for numerical optimization problems with different scale.

To provide more accurate conclusions, Table 7 shows a multi-problem based pairwise statistical analysis that is computed by the Wilcoxon signed-rank test 60] at a significance level of $\alpha=0.05$. The computation of $p$-values is performed according to the mean values generated through 30 runs. The results show that the ACVO performs the best among counterpart algorithms on test problems with three dimensions 10, 30 and 50. This highlights that ACVO can efficiently optimize the test problems with diverse dimensions. The $p$-values obtained in $D=30$ and 50 show that ACVO is an effective method in optimizing medium and large dimension problems. 
Table 3: Results obtained by the ACVO and comparison algorithms on test functions, when $D=10$

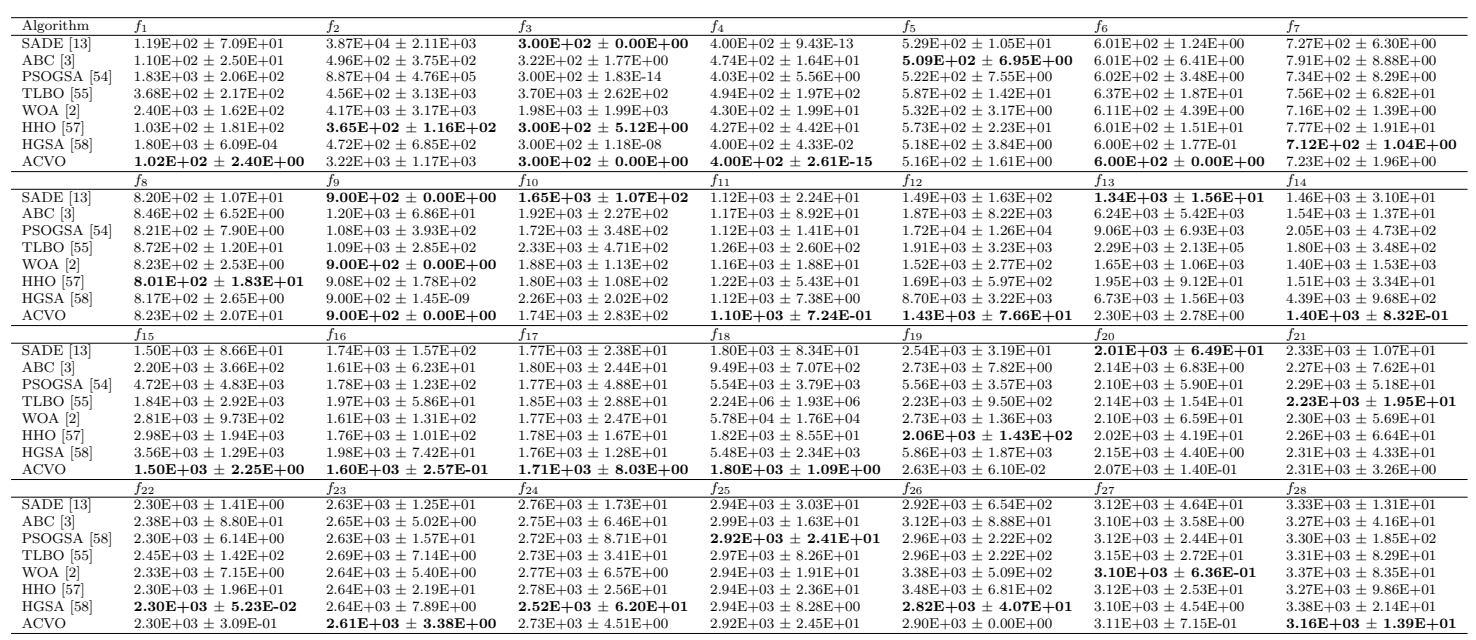

Table 4: Results obtained by the ACVO and comparison algorithms on test functions, when $D=30$

\begin{tabular}{|c|c|c|c|c|c|c|c|}
\hline Algorithm & $f_{1}$ & $f_{2}$ & $f_{3}$ & $f_{4}$ & & & \\
\hline SADE [13] & $1.96 \mathrm{E}+03 \pm 1.75 \mathrm{E}+03$ & $4.11 \mathrm{E}+02 \pm 3.30 \mathrm{E}+01$ & $3.05 \mathrm{E}+02 \pm 3.45 \mathrm{E}+00$ & $4.36 \mathrm{E}+02 \pm 3.10 \mathrm{E}+01$ & $6.78 \mathrm{E}+02 \pm 4.68 \mathrm{E}+01$ & $6.28 \mathrm{E}+02 \pm 7.54 \mathrm{E}+00$ & $9.00 \mathrm{E}+02 \pm 5.24 \mathrm{E}+01$ \\
\hline 3] & $3.08 \mathrm{E}+03 \pm 1.91 \mathrm{E}+01$ & $4.25 \mathrm{E}+02 \pm 1.10 \mathrm{E}+01$ & $3.00 \mathrm{E}+02 \pm 1.25 \mathrm{E}+02$ & $4.14 \mathrm{E}+02 \pm 5.23 \mathrm{E}+01$ & $5.11 \mathrm{E}+02 \pm 2.48 \mathrm{E}+01$ & $6.03 \mathrm{E}+02 \pm 2.45 \mathrm{E}+00$ & $7.50 \mathrm{E}+02 \pm 1.94 \mathrm{E}+01$ \\
\hline 5 A 54$]$ & $\begin{array}{l}2.74 \mathrm{E}+03 \pm 8.83 \mathrm{E}+02 \\
2.80 \mathrm{E}+03+2.02 \mathrm{E}+02\end{array}$ & $4.12 \mathrm{E}+03 \pm 3.26 \mathrm{E}+03$ & $3.56 \mathrm{E}+03 \pm 7.87 \mathrm{E}+03$ & $1.04 \mathrm{E}+03 \pm 5.05 \mathrm{E}+02$ & & $6.24 \mathrm{E}+02 \pm 8.94 \mathrm{E}+00$ & 9.72E $+02 \pm 6.32 \mathrm{E}+01$ \\
\hline & $\begin{array}{l}2.80 \mathrm{E}+03 \pm 2.00 \mathrm{E}+02 \\
1.66 \mathrm{E}+04 \pm 2.00 \mathrm{E}+03\end{array}$ & $\begin{array}{l}4.38 \mathrm{E}+03 \pm 1.60 \mathrm{E}+01 \\
4.17 \mathrm{E}+3 \pm 3.60 \mathrm{E}+01\end{array}$ & $\begin{array}{l}3.15 \mathrm{E}+02 \pm 1.50 \mathrm{E}+01 \\
3.84 \mathrm{E}+2+1.33 \mathrm{E}+02\end{array}$ & $\begin{array}{l}4.35 \mathrm{E}+02 \pm 3.92 \mathrm{E}+02 \\
4.60 \mathrm{E}+02+6.75 \mathrm{E}+02\end{array}$ & $\begin{array}{l}5.98 \mathrm{E}+02 \pm 3.93 \mathrm{E}+01 \\
5.75 \mathrm{E}+02+2.68 \mathrm{E}+00\end{array}$ & $6.03 \mathrm{E}+02 \pm 4.77 \mathrm{E}-01$ & $\begin{array}{r}7.95 \mathrm{E}+02 \pm 9.37 \mathrm{E}+00 \\
\end{array}$ \\
\hline HHO & $4.76 \mathrm{E}+04 \pm 1.88 \mathrm{E}+03$ & $4.55 \mathrm{E}+03 \pm 5.00 \mathrm{E}+01$ & $\begin{array}{l}3.84 \mathrm{E}+2 \pm 2 \pm 1.33 \mathrm{E}+02 \\
3.57 \mathrm{E}+02 \pm 1.90 \mathrm{E}+01\end{array}$ & $\begin{array}{l}4.60 \mathrm{E}+022 \pm 6.78 \mathrm{E}+01 \\
4.41 \mathrm{E}+22 \pm 2.43 \mathrm{E}+01\end{array}$ & $\begin{array}{l}5.75 \mathrm{E}+02 \pm 2.68 \mathrm{E}+00 \\
5.75 \mathrm{E}+02 \pm 7.43 \mathrm{E}+00\end{array}$ & $\begin{array}{l}6.53 \mathrm{E}+02 \pm 7.12 \mathrm{E}+00 \\
6.00 \mathrm{E}+02 \pm 4.01 \mathrm{E}-01\end{array}$ & $\begin{array}{l}1.39 \mathrm{E}+0339.909 \mathrm{E}+01 \\
8.59 \mathrm{E}+02+1.50 \mathrm{E}+01\end{array}$ \\
\hline & $1.63 \mathrm{E}+03 \pm 9.80 \mathrm{E}+01$ & $2.68 \mathrm{E}+03 \pm 2.50 \mathrm{E}+03$ & $4.36 \mathrm{E}+04 \pm 5.49 \mathrm{E}+03$ & $5.19 \mathrm{E}+02 \pm 2.63 \mathrm{E}+00$ & $6.53 \mathrm{E}+02 \pm 1.28 \mathrm{E}+01$ & $6.08 \mathrm{E}$ & $7.41 \mathrm{E}+\mathbf{0 2}+\mathbf{3 . 0 1 E}+\mathbf{0 0}$ \\
\hline & $1.71 \mathrm{E}+03 \pm 1.69 \mathrm{E}+03$ & $4.67 \mathrm{E}+03 \pm 2.17 \mathrm{E}+01$ & $3.00 \mathrm{E}+02 \pm 2.84 \mathrm{E}-14$ & $4.66 \mathrm{E}+02 \pm 4.23 \mathrm{E}+01$ & $5.50 \mathrm{E}+02 \pm 8.23 \mathrm{E}+00$ & $6.00 \mathrm{E}+02 \pm 1.69 \mathrm{E}-03$ & $7.65 \mathrm{E}+02 \pm 1.27 \mathrm{E}+01$ \\
\hline & & & & & & & \\
\hline & $61 \mathrm{E}+02 \pm 3.60 \mathrm{E}+01$ & & & $1.16 \mathrm{E}+03 \pm 1.48 \mathrm{E}+01$ & $2.85 \mathrm{E}+04 \pm 1.82 \mathrm{E}+04$ & $2.45 \mathrm{E}+04 \pm 7.37 \mathrm{E}+03$ & $1.80 \mathrm{E}+03 \pm 1.07 \mathrm{E}+02$ \\
\hline & $E+01$ & $3.16 \mathrm{E}$ & & & & & \\
\hline & & & & & & & \\
\hline & & & $5.22 \mathrm{E}+03 \pm 1.08 \mathrm{E}+02$ & & & & $1.47 \mathrm{E}+03 \pm 1.70 \mathrm{E}+$ \\
\hline & $8.56 \mathrm{E}+02 \pm 3.25 \mathrm{E}+00$ & $9.02 \mathrm{E}+02 \pm 7.52 \mathrm{E}+00$ & $5.21 \mathrm{E}+03 \pm 1.46 \mathrm{E}+01$ & $1.17 \mathrm{E}+03 \pm 2.96 \mathrm{E}+01$ & $1.48 \mathrm{E}+06 \pm 4.14 \mathrm{E}+05$ & $3.02 \mathrm{E}+04 \pm 2.70 \mathrm{E}+03$ & $1.52 \mathrm{E}+03 \pm 5.74 \mathrm{E}+02$ \\
\hline & $\begin{array}{l}9.00 \mathrm{E}+ \\
9.170\end{array}$ & $9.00 \mathrm{E}-$ & $\begin{array}{l}6.21 \mathrm{E} \\
4.20\end{array}$ & $\begin{array}{l}1.30 \mathrm{E}+03 \\
1.20 \mathrm{E}+03\end{array}$ & $\begin{array}{l}.88 \mathrm{ge}+04 \pm 2.61 \mathrm{~F} \\
1.29 \mathrm{E}+05 \pm 8.15 \mathrm{~F}\end{array}$ & 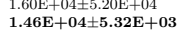 & $\begin{array}{l}+9.24 \mathrm{E}+02 \\
+3.05 \mathrm{E}+03\end{array}$ \\
\hline & $8.65 \mathrm{E}+02 \pm 2.38 \mathrm{E}+00$ & $9.07 \mathrm{E}+02 \pm 2.49 \mathrm{E}+00$ & $5.02 \mathrm{E}+03 \pm 5.53 \mathrm{E}+02$ & $1.15 \mathrm{E}+03 \pm 3.13 \mathrm{E}+01$ & $2.10 \mathrm{E}+04 \pm 1.99 \mathrm{E}+04$ & $2.33 \mathrm{E}+04 \pm 1.82 \mathrm{E}+04$ & $1.49 \mathrm{E}+03 \pm 3.89 \mathrm{E}+01$ \\
\hline & & & & & & & \\
\hline & & & & & & & $\overline{\mathrm{E}+00}$ \\
\hline & & & & & & & \\
\hline & & & & & & & \\
\hline & & & & & & & $E+02$ \\
\hline & & & & & & & \\
\hline & & & & & & & $10 \mathrm{E}+01$ \\
\hline & $\begin{array}{l}2.20 \mathrm{E}+\mathrm{O} \\
1.94 \mathrm{E}+0\end{array}$ & $\begin{array}{l}2.83 \mathrm{E}+ \\
2.18 \mathrm{E}-\mathrm{r}\end{array}$ & $\begin{array}{l}2.76 \mathrm{E}- \\
1.75 \mathrm{E}\end{array}$ & $\begin{array}{l}6.16 \mathrm{E} \\
4.38 \mathrm{E}\end{array}$ & $\begin{array}{l}3.42 \mathrm{E}-\mathrm{E}-1 \\
3.96 \mathrm{~s}\end{array}$ & & \\
\hline & & & & & & & \\
\hline & & & & & & & \\
\hline & & & & & & & \\
\hline & & & & & & & \\
\hline & & & & & & & \\
\hline & & & & & & & \\
\hline & & & & & & & \\
\hline & $2.30 \mathrm{E}+03+0.00 \mathrm{E}+00$ & & & & & & \\
\hline & & & $2.86 \mathrm{E}+03 \pm 1.59 \mathrm{E}+01$ & $2.89 \mathrm{E}+03 \pm 1.06 \mathrm{E}-0$ & $5.29 \mathrm{E}+03 \pm 1.51 \mathrm{E}+03$ & $3.23 \mathrm{E}+03 \pm 1.19 \mathrm{E}+01$ & $3.55 \mathrm{E}+03 \pm 5.96 \mathrm{E}+01$ \\
\hline
\end{tabular}

Figure 6 shows the algorithms' aggregate performance on test problems. The horizontal axis shows the $k$ th rank of algorithms. The vertical axis represents the number of functions on which the algorithm gained the $k$ th rank based on the Wilcoxon signed-rank test. As shown in Fig 6, the ACVO algorithm is the top-1 performer among most functions. This shows that the solution quality of the ACVO is better than its counterparts. The second rank belongs to SADE on 10 and $30 D$ functions, and HGSA on $50 D$ functions. The 
Table 5: Results obtained by the ACVO and comparison algorithms on test functions, when $D=50$

\begin{tabular}{|c|c|c|c|c|c|c|c|}
\hline Algorithm & & & & & & & \\
\hline SADE [1] & $1.76 \mathrm{E}+03 \pm 1.25 \mathrm{E}+$ & $1.01 \mathrm{E}+03 \pm 4.23 \mathrm{E}+02$ & $3.11 \mathrm{E}+03 \pm 4.80 \mathrm{E}+02$ & $5.02 \mathrm{E}+02 \pm 7.52 \mathrm{E}+01$ & & $+02 \pm 4.60 \mathrm{E}+01$ & $7.70 \mathrm{E}+02 \pm 1.63 \mathrm{E}+01$ \\
\hline $\mathrm{ABC}$ 3] & $2.10 \mathrm{E}+03 \pm 1.13 \mathrm{E}+02$ & $9.56 \mathrm{E}+02 \pm 6.50 \mathrm{E}+05$ & $2.44 \mathrm{E}+03 \pm 3.10 \mathrm{E}+04$ & $7.67 \mathrm{E}+02 \pm 2.86 \mathrm{E}+01$ & $8.80 \mathrm{E}+02 \pm 3.18 \mathrm{E}+01$ & $6.35 \mathrm{E}+02 \pm 5.72 \mathrm{E}+01$ & $8.00 \mathrm{E}+02 \pm 2.40 \mathrm{E}+01$ \\
\hline PSOGSA [54] & $4.66 \mathrm{E}+03 \pm 2.39 \mathrm{E}+03$ & $1.69 \mathrm{E}+09 \pm 4.33 \mathrm{E}+09$ & $3.67 \mathrm{E}+04 \pm 6.07 \mathrm{E}+04$ & $3.70 \mathrm{E}+03 \pm 2.22 \mathrm{E}+03$ & $7.87 \mathrm{E}+02 \pm 7.88 \mathrm{E}+01$ & $6.35 \mathrm{E}+02 \pm 7.66 \mathrm{E}+00$ & 1. $46 \mathrm{E}+03 \pm 1.51 \mathrm{E}+02$ \\
\hline $\begin{array}{l}\text { TLBO } 554] \\
\text { WOA }\end{array}$ & 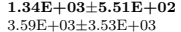 & 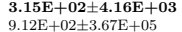 & $\begin{array}{l}\mathbf{3 . 0 0 E}+\mathbf{0 2} \mathbf{0 . 0 . 0 0 0}+\mathbf{0 0}+\mathbf{0 0} \\
8.39 \mathrm{E}+04+373 \mathrm{E}+03\end{array}$ & $\begin{array}{l}5.19 \mathrm{E}+02 \pm 9.53 \mathrm{E}+02 \\
2.13 \mathrm{E}+03 \pm 4.90 \mathrm{E}+02\end{array}$ & $\begin{array}{l}1.09 \mathrm{E}+03 \pm 4.26 \mathrm{E}+01 \\
9.36 \mathrm{E}+02 \pm 2.14 \mathrm{E}+01\end{array}$ & $\begin{array}{l}6.29 \mathrm{E}+02 \pm 4.79 \mathrm{E}+00 \\
6.40 \mathrm{E}+02 \pm 2.43 \mathrm{E}+00\end{array}$ & $1.40 \mathrm{E}+03 \pm 1.29 \mathrm{E}+02$ \\
\hline $\mathrm{HHO}$ गे & $1.74 \mathrm{E}+03 \pm 3.66 \mathrm{E}+05$ & $\begin{array}{l}.12 \mathrm{E}+02 \pm 3.67 \mathrm{E}+03 \\
1.14 \mathrm{E}+03 \pm 3.60 \mathrm{E}+03\end{array}$ & $\begin{array}{l}5.83 \mathrm{E}+04 \pm 3.35 \mathrm{E}+03 \\
5.03 \mathrm{E}+04 \pm 3.35 \mathrm{E}+04\end{array}$ & $\begin{array}{l}.13 \mathrm{E}+03 \pm 4.90 \mathrm{E}+02 \\
6.27 \mathrm{E}+02 \pm 4.58 \mathrm{E}+01\end{array}$ & $\begin{array}{l}.3 .5 \mathrm{E}+02 \pm 2.14 \mathrm{E}+01 \\
8.77 \mathrm{E}+02 \pm 4.76 \mathrm{E}+01\end{array}$ & $\begin{array}{l}6.4 \mathrm{VE}+02 \pm 2.43 \mathrm{E}+00 \\
6.21 \mathrm{E}+02 \pm 9.34 \mathrm{E}+00\end{array}$ & $\begin{array}{l}1.38 \mathrm{E}+03 \pm 7.82 \mathrm{E}+01 \\
1.61 \mathrm{E}+3 \pm 7.57 \mathrm{E}+01\end{array}$ \\
\hline & $2.10 \mathrm{E}+03 \pm 9.10 \mathrm{E}+02$ & $9.42 \mathrm{E}+02 \pm 1.17 \mathrm{E}+03$ & $1.19 \mathrm{E}+05 \pm 1.15 \mathrm{E}+04$ & $6.02 \mathrm{E}+02 \pm 2.91 \mathrm{E}+01$ & $7.68 \mathrm{E}+02 \pm 1.36 \mathrm{E}+01$ & $6.25 \mathrm{E}+02 \pm 3.97 \mathrm{E}+00$ & $7.70 \mathrm{E}+02 \pm 3.44 \mathrm{E}+00$ \\
\hline $\mathrm{ACV}$ & $1.95 \mathrm{E}+03 \pm 1.42 \mathrm{E}+02$ & $1.02 \mathrm{E}+03 \pm 7.63 \mathrm{E}+05$ & $3.00 \mathrm{E}+02 \pm 0.00 \mathrm{E}+00$ & $4.73 \mathrm{E}+02 \pm 6.40 \mathrm{E}+01$ & $6.93 \mathrm{E}+02 \pm 9.77 \mathrm{E}+01$ & $6.23 \mathrm{E}+02 \pm 5.46 \mathrm{E}-02$ & $7.88 \mathrm{E}+02 \pm 2.27 \mathrm{E}+01$ \\
\hline & & & & & & & \\
\hline & $1.01 \mathrm{E}+03 \pm 2.71 \mathrm{E}+01$ & $1.15 \mathrm{E}+03 \pm 2.37 \mathrm{E}+02$ & $9.60 \mathrm{E}+03 \pm 3.30 \mathrm{E}+03$ & $1.22 \mathrm{E}+03 \pm 5.63 \mathrm{E}+01$ & $7.71 \mathrm{E}+05 \pm 1.19 \mathrm{E}+05$ & $1.80 \mathrm{E}+04 \pm 1.47 \mathrm{E}+04$ & \\
\hline & & & & & & & \\
\hline & & & & & & & \\
\hline TLB & $1.10 \mathrm{E}-$ & & & & & & \\
\hline $\begin{array}{l}\text { WOA } \\
\text { HHO }\end{array}$ & 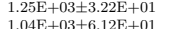 & & & & & & $9.82 \mathrm{E}+05 \pm 3.39 \mathrm{E}+05$ \\
\hline 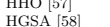 & 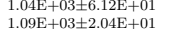 & $\begin{array}{l}1.57 \mathrm{E} \\
9.00 \mathrm{E}\end{array}$ & $\begin{array}{l}6.87 \mathrm{E}- \\
6.83 \mathrm{E}-\mathrm{T}\end{array}$ & $\begin{array}{ll}34 \mathrm{E}+01 \\
2 \mathrm{E}+01\end{array}$ & $\begin{array}{l}=1.02 \mathrm{E}+04 \\
-3.35 \mathrm{E}+05\end{array}$ & $\begin{array}{l}1.26 \mathrm{E}+05 \pm 7.25 \mathrm{E}+04 \\
\mathbf{1 . 9 0 E + 0 3 + 3 8}+\mathbf{0 3}\end{array}$ & $\begin{array}{l}2.19 \mathrm{E}+05 \pm 1.59 \mathrm{E}+04 \\
2.71 \mathrm{E}+04+3.76 \mathrm{E}+04\end{array}$ \\
\hline & $1.01 \mathrm{E}+03 \pm 1.93 \mathrm{E}+02$ & 9.00E $+02+3.14 \mathrm{E}+00$ & $6.80 \mathrm{E}+33 \pm 4.31 \mathrm{E}+02$ & $1.29 \mathrm{E}+03 \pm 2.05 \mathrm{E}+01$ & $5.60 \mathrm{E}+04 \pm 3.11 \mathrm{E}+04$ & $2.02 \mathrm{E}+03 \pm 1.74 \mathrm{E}+03$ & $6.11 \mathrm{E}+03 \pm 2.34 \mathrm{E}+03$ \\
\hline & & & & & & & \\
\hline & 8.8 & & & & & $\mathrm{E}+02$ & $\overline{E+02}$ \\
\hline & & & & & & & \\
\hline & & & & & & & \\
\hline & & & & & & & \\
\hline & & & & & & & \\
\hline & & & & $.74 \mathrm{E}$ & & & $+03 \pm 3.22 \mathrm{E}+01$ \\
\hline & $36 \mathrm{E}+$ & $09 \mathrm{E}+03 \pm 2.33 \mathrm{E}+02$ & $3.56 \mathrm{E}+03 \pm 4.16 \mathrm{E}+02$ & $1.10 \mathrm{E}+05 \pm 1.05 \mathrm{E}+04$ & $9.52 \mathrm{E}+03 \pm 9.171$ & $3.35 \mathrm{E}+03 \pm 1.68 \mathrm{E}+02$ & $2.45 \mathrm{E}+03 \pm 3.01 \mathrm{E}+02$ \\
\hline & & & & & & & \\
\hline & & & & & & & \\
\hline & & & & & & & \\
\hline & & & & & & & \\
\hline & & & & & & & \\
\hline & & & & & & & \\
\hline & & & & & & & \\
\hline & $03+2.79 \mathrm{E}+03$ & 列 & $03+1.86 \mathrm{E}+01$ & & & & $329>>29$ \\
\hline
\end{tabular}

Table 6: Comparison of the algorithms in terms of the average and final ranks computed by Friedman test

\begin{tabular}{|c|c|c|c|c|c|c|}
\hline \multirow[b]{2}{*}{ Algorithm } & \multicolumn{2}{|c|}{$10 D$} & \multicolumn{2}{|c|}{$30 D$} & \multicolumn{2}{|c|}{$50 D$} \\
\hline & Average rank & Final rank & Average rank & Final rank & Average rank & Final rank \\
\hline SADE 13] & 3.589 & 2 & 3.828 & 2 & 3.304 & \\
\hline $\mathrm{ABC} 3]$ & 5.321 & 7 & 4.638 & 5 & 6.142 & 8 \\
\hline PSOGSA 54] & 4.893 & 6 & 6.327 & 8 & 5.357 & 5 \\
\hline $\mathrm{HHO} 57$ & 4.321 & 3 & 4.603 & 4 & 4.625 & 4 \\
\hline WOA 201 & 4.839 & 5 & 5.172 & 7 & 5.875 & 7 \\
\hline TLBO 55] & 6.107 & 8 & 4.724 & 6 & 5.518 & 6 \\
\hline HGSA & 4.393 & 4 & 3.948 & 3 & 3.143 & 2 \\
\hline $\mathrm{ACVO}-$ & 2.536 & 1 & 2.759 & 1 & 2.036 & 1 \\
\hline
\end{tabular}

Table 7: Statistical results obtained by the Wilcoxon signed rank test between ACVO and comparison algorithms in $D=10,30$ and 50 dimensions, and $\alpha=$ 0.05

\begin{tabular}{|c|c|c|c|c|c|c|c|c|c|}
\hline \multirow{2}{*}{ ACVO vs. } & \multicolumn{3}{|c|}{$D=10$} & \multicolumn{3}{|c|}{$D=30$} & \multicolumn{3}{|c|}{$D=50$} \\
\hline & $T+$ & $T-$ & $p$-value & $T+$ & $T-$ & $p$-value & $T+$ & $T-$ & $p$-value \\
\hline $\begin{array}{ll}\text { SADE } & 13 \\
\end{array}$ & 241 & 84 & $3.49 \mathrm{E}-02$ & 299 & 107 & $2.85 \mathrm{E}-02$ & 297 & 109 & $3.24 \mathrm{E}-02$ \\
\hline $\mathrm{ABC} 3]$ & 357 & 49 & $4.40 \mathrm{E}-04$ & 319.5 & 86.5 & $8.04 \mathrm{E}-03$ & 396 & 10 & $1.00 \mathrm{E}-05$ \\
\hline PSOGSA 54] & 348 & 30 & $1.40 \mathrm{E}-04$ & 421.5 & 13.5 & $1.00 \mathrm{E}-05$ & 388 & 18 & $1.00 \mathrm{E}-05$ \\
\hline TLBO 55 & 356 & 50 & $5.00 \mathrm{E}-04$ & 349.5 & 56.5 & $8.40 \mathrm{E}-04$ & 387 & 19 & $1.00 \mathrm{E}-05$ \\
\hline WOA $2 \pi$ & 335 & 43 & $4.40 \mathrm{E}-04$ & 362 & 44 & $3.00 \mathrm{E}-04$ & 381 & 25 & $1.00 \mathrm{E}-05$ \\
\hline НHO & 279 & 99 & $3.08 \mathrm{E}-02$ & 330.5 & 55.5 & $3.74 \mathrm{E}-03$ & 261 & 90 & $3.00 \mathrm{E}-02$ \\
\hline HGSA 58$]$ & 231 & 69 & $2.09 \mathrm{E}-02$ & 292.5 & 113.5 & $4.14 \mathrm{E}-02$ & 227 & 73 & $2.78 \mathrm{E}-02$ \\
\hline
\end{tabular}

third rank on 10, 30 and $50 D$ functions respectively belongs to HHO, HGSA and SADE.

Tables 8 and 9 list the unadjusted and adjusted $p$-values 60 obtained by counterpart algorithms in comparison with the ACVO on benchmarks. The computation is performed according to the mean cost values. The re- 


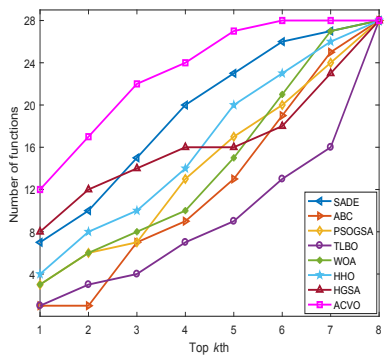

(a)

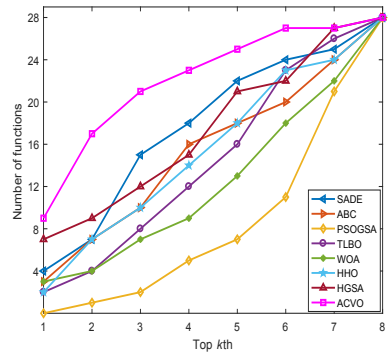

(b)

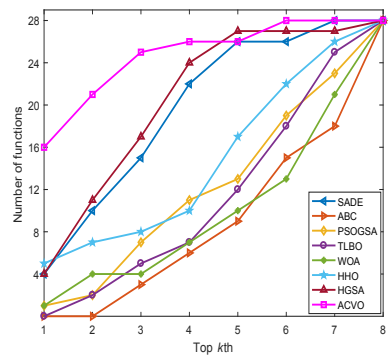

(c)

Fig. 6: The box-and-whisker plots of solutions reported by ACVO and counterpart algorithms on $f_{4}, f_{10}, f_{22}$ and $f_{28}$ test functions with 10,30 and 50 dimensions

Table 8: Unadjusted $p$-values of comparison algorithms where the ACVO is the control algorithm

\begin{tabular}{|c|c|c|c|c|c|c|c|c|}
\hline \multirow{2}{*}{ Dimension } & \multirow{2}{*}{ Statistics } & \multicolumn{7}{|c|}{ Algorithm } \\
\hline & & $\begin{array}{ll}\text { SADE } & 13 \\
\end{array}$ & $\mathrm{ABC} 3$ & PSOGSA 54] & TLBO 55] & WOA 2 & HHO 57$]$ & HGSA 58 \\
\hline \multirow[t]{4}{*}{10} & $p$-value & $1.08 \mathrm{E}-01$ & $2.09 \mathrm{E}-\mathrm{U} 5$ & $3.17 \mathrm{E}-04$ & $4.88 \mathrm{E}-08$ & $4.34 \mathrm{E}-04$ & $6.38 \mathrm{E}-03$ & $4.56 \mathrm{E}-\mathrm{U3}$ \\
\hline & $p_{\text {Bonf }}$ & 7.53E-01 & $1.46 \mathrm{E}-04$ & $2.22 \mathrm{E}-03$ & $3.42 \mathrm{E}-07$ & 3.03E-03 & $4.46 \mathrm{E}-02$ & $3.19 \mathrm{E}-02$ \\
\hline & $p_{\text {Holm }}$ & $1.08 \mathrm{E}-01$ & $1.25 \mathrm{E}-04$ & $1.59 \mathrm{E}-03$ & $3.42 \mathrm{E}-07$ & $1.73 \mathrm{E}-03$ & $1.37 \mathrm{E}-02$ & $1.37 \mathrm{E}-02$ \\
\hline & $p_{\text {Hochberg }}$ & $1.08 \mathrm{E}-01$ & $1.25 \mathrm{E}-04$ & $1.59 \mathrm{E}-03$ & $3.42 \mathrm{E}-07$ & $1.73 \mathrm{E}-03$ & $1.28 \mathrm{E}-02$ & $1.28 \mathrm{E}-02$ \\
\hline \multirow[t]{4}{*}{30} & $p$-value & $9.66 \mathrm{E}-02$ & $3.48 \mathrm{E}-03$ & $2.89 \mathrm{E}-08$ & $2.25 \mathrm{E}-03$ & $1.75 \mathrm{E}-04$ & $4.13 \mathrm{E}-03$ & $6.44 \mathrm{E}-02$ \\
\hline & $p_{\text {Bonf }}$ & $6.76 \mathrm{E}-01$ & $2.44 \mathrm{E}-02$ & $2.02 \mathrm{E}-07$ & $1.57 \mathrm{E}-02$ & $1.23 \mathrm{E}-03$ & $2.89 \mathrm{E}-02$ & $4.51 \mathrm{E}-01$ \\
\hline & & & & & & & & $1.29 \mathrm{E}-01$ \\
\hline & $p_{\text {Hochberg }}$ & $9.66 \mathrm{E}-02$ & $1.24 \mathrm{E}-02$ & $2.02 \mathrm{E}-07$ & $1.12 \mathrm{E}-02$ & $1.05 \mathrm{E}-03$ & $1.24 \mathrm{E}-02$ & $9.66 \mathrm{E}-02$ \\
\hline \multirow[t]{4}{*}{50} & $p$-value & & $3.52 \mathrm{E}-10$ & & & $4.50 \mathrm{E}-09$ & $7.65 \mathrm{E}-05$ & $9.08 \mathrm{E}-02$ \\
\hline & & $99 \mathrm{E}-01$ & $2.47 \mathrm{E}-09$ & $2.73 \mathrm{E}-06$ & $7.30 \mathrm{E}-07$ & $3.15 \mathrm{E}-08$ & $5.35 \mathrm{E}-04$ & $6.36 \mathrm{E}-01$ \\
\hline & & $1.06 \mathrm{E}-01$ & $2.47 \mathrm{E}-09$ & $1.56 \mathrm{E}-06$ & $5.22 \mathrm{E}-07$ & $2.70 \mathrm{E}-08$ & $2.29 \mathrm{E}-04$ & $1.06 \mathrm{E}-01$ \\
\hline & & $9.08 \mathrm{E}-02$ & $2.47 \mathrm{E}-09$ & $1.56 \mathrm{E}-06$ & $5.22 \mathrm{E}-07$ & $2.70 \mathrm{E}-08$ & $2.29 \mathrm{E}-04$ & $9.08 \mathrm{E}-02$ \\
\hline
\end{tabular}

Table 9: Adjusted $p$-values of comparison algorithms where the ACVO is the control algorithm

\begin{tabular}{|c|c|c|c|c|c|c|c|c|}
\hline \multirow{2}{*}{ Dimension } & \multirow{2}{*}{ Statistics } & \multicolumn{7}{|c|}{ Algorithm } \\
\hline & & SADE 13 & $\mathrm{ABC}$ 3] & PSOGSA 54] & TLBO 55] & WOA 2] & $\mathrm{HHO}$ 57] & HGSA 58, \\
\hline \multirow[t]{4}{*}{10} & $p$-value & $6.75 \mathrm{E}-01$ & $4.79 \mathrm{E}-03$ & $4.89 \mathrm{E}-04$ & $1.03 \mathrm{E}-05$ & $2.21 \mathrm{E}-03$ & $1.29 \mathrm{E}-01$ & $4.29 \mathrm{E}-03$ \\
\hline & $p_{\text {Bonf }}$ & $4.72 \mathrm{E}+00$ & $3.35 \mathrm{E}-02$ & $3.42 \mathrm{E}-03$ & $7.22 \mathrm{E}-05$ & $1.54 \mathrm{E}-02$ & $9.00 \mathrm{E}-01$ & $3.00 \mathrm{E}-02$ \\
\hline & $p_{\text {Holm }}$ & $6.75 \mathrm{E}-01$ & $1.72 \mathrm{E}-02$ & $2.93 \mathrm{E}-03$ & $7.22 \mathrm{E}-05$ & $1.10 \mathrm{E}-02$ & 2.57E-01 & $1.72 \mathrm{E}-02$ \\
\hline & & $6.75 \mathrm{E}-01$ & $1.44 \mathrm{E}-02$ & $2.93 \mathrm{E}-03$ & $7.22 \mathrm{E}-05$ & $1.10 \mathrm{E}-02$ & $2.57 \mathrm{E}-01$ & $1.44 \mathrm{E}-02$ \\
\hline \multirow[t]{4}{*}{30} & $p$-value & $1.37 \mathrm{E}-01$ & $9.40 \mathrm{E}-03$ & $1.28 \mathrm{E}-08$ & $6.05 \mathrm{E}-03$ & $1.64 \mathrm{E}-03$ & $5.04 \mathrm{E}-02$ & $1.70 \mathrm{E}-02$ \\
\hline & $p_{\text {Bonf }}$ & $9.56 \mathrm{E}-01$ & $6.58 \mathrm{E}-02$ & $8.99 \mathrm{E}-08$ & $4.24 \mathrm{E}-02$ & $1.15 \mathrm{E}-02$ & 3.53E-01 & $1.19 \mathrm{E}-01$ \\
\hline & & 1.37E-01 & $3.76 \mathrm{E}-02$ & $8.99 \mathrm{E}-08$ & 3.03E-02 & $9.87 \mathrm{E}-03$ & $1.01 \mathrm{E}-01$ & $5.10 \mathrm{E}-02$ \\
\hline & $\begin{array}{l}\text { Holm } \\
p_{\text {Hochberg }}\end{array}$ & $1.37 \mathrm{E}-01$ & 3.76E-02 & $8.99 \mathrm{E}-08$ & 3.03E-02 & $9.87 \mathrm{E}-03$ & $1.01 \mathrm{E}-01$ & $5.10 \mathrm{E}-02$ \\
\hline \multirow[t]{4}{*}{50} & $p$-value & $1.70 \mathrm{E}-01$ & $5.38 \mathrm{E}-10$ & $4.21 \mathrm{E}-07$ & $5.45 \mathrm{E}-06$ & $4.98 \mathrm{E}-09$ & $2.01 \mathrm{E}-03$ & $7.50 \mathrm{E}-02$ \\
\hline & & $1.19 \mathrm{E}+00$ & 3.77E-09 & $2.95 \mathrm{E}-06$ & $3.82 \mathrm{E}-05$ & $3.49 \mathrm{E}-08$ & $1.41 \mathrm{E}-02$ & $5.25 \mathrm{E}-01$ \\
\hline & & $1.70 \mathrm{E}-01$ & 3.77E-09 & $2.11 \mathrm{E}-06$ & $2.18 \mathrm{E}-05$ & $2.99 \mathrm{E}-08$ & 6.03E-03 & $1.50 \mathrm{E}-01$ \\
\hline & $p_{\text {Hochberg }}$ & 1.70E-01 & 3.77E-09 & $2.11 \mathrm{E}-06$ & $2.18 \mathrm{E}-05$ & $2.99 \mathrm{E}-08$ & 6.03E-03 & $1.50 \mathrm{E}-01$ \\
\hline
\end{tabular}

sults demonstrate that ACVO performs well on most functions, matching or exceeding the best result reported by its counterparts.

The contrast estimation based on medians for algorithms over test problems is summarized in Table 10. The objective of contrast estimation is to show the global performance of the algorithms by computing the magnitudes of the differences among their performances 60]. This test shows how well one algorithm compared to another one. The results highlight the ACVO as 
Table 10: Contrast estimation results for the comparison algorithms

\begin{tabular}{|c|c|c|c|c|c|c|c|c|c|}
\hline Dimension & Algorithm & SADE $\overline{13}$ & $\mathrm{ABC}$ 3] & PSOGSA 54 & TLBO $\sqrt{55}$ & WOA 2] & HHO $\overline{57}$ & \begin{tabular}{ll|} 
HGSA & 58
\end{tabular} & ACVO \\
\hline \multirow{8}{*}{10} & SADE 13 & 0 & $2.15 \mathrm{E}-05$ & $1.59 \mathrm{E}-05$ & $4.13 \mathrm{E}-05$ & $1.47 \mathrm{E}-\frac{10}{5}$ & $8.26 \mathrm{E}-06$ & $1.31 \mathrm{E}-05$ & $-3.82 \mathrm{E}-06$ \\
\hline & $\mathrm{ABC}[3]$ & $-2.15 \mathrm{E}-05$ & 0 & $-5.61 \mathrm{E}-06$ & $1.98 \mathrm{E}-05$ & $\begin{array}{l}-6.83 \mathrm{E}-06 \\
-\end{array}$ & $-1.32 \mathrm{E}-05$ & $-8.37 \mathrm{E}-06$ & $-2.53 \mathrm{E}-05$ \\
\hline & PSOGSA [54] & $-1.59 \mathrm{E}-05$ & $5.61 \mathrm{E}-06$ & 0 & $2.55 \mathrm{E}-05$ & $-1.21 \mathrm{E}-06$ & $-7.60 \mathrm{E}-06$ & $-2.75 \mathrm{E}-06$ & $-1.97 \mathrm{E}-05$ \\
\hline & TLBO $\sqrt{55}$ & $-4.13 \mathrm{E}-05$ & $-1.98 \mathrm{E}-05$ & $-2.55 \mathrm{E}-05$ & 0 & $-2.67 \mathrm{E}-05$ & $-3.31 \mathrm{E}-05$ & $-2.82 \mathrm{E}-05$ & $-4.51 \mathrm{E}-05$ \\
\hline & WOA 2 & $-1.47 \mathrm{E}-05$ & $6.83 \mathrm{E}-06$ & $1.21 \mathrm{E}-06$ & $2.67 \mathrm{E}-05$ & 0 & $-6.39 \mathrm{E}-06$ & $-1.54 \mathrm{E}-06$ & $-1.85 \mathrm{E}-05$ \\
\hline & & $-8.26 \mathrm{E}-06$ & $1.32 \mathrm{E}-05$ & 7.60E-06 & $3.31 \mathrm{E}-05$ & $6.39 \mathrm{E}-06$ & & $4.85 \mathrm{E}-06$ & $-1.21 \mathrm{E}-05$ \\
\hline & HGSA 58$]$ & $-1.31 \mathrm{E}-05$ & 8.37E-06 & $2.75 \mathrm{E}$ & $2.82 \mathrm{E}-05$ & & $-4.85 \mathrm{E}-06$ & & $-1.69 \mathrm{E}-05$ \\
\hline & ACVO & $3.82 \mathrm{E}-06$ & $2.53 \mathrm{E}-05$ & $1.97 \mathrm{E}-05$ & $4.51 \mathrm{E}-05$ & $1.85 \mathrm{E}-05$ & $1.21 \mathrm{E}-05$ & $1.69 \mathrm{E}-05$ & 0 \\
\hline \multirow{8}{*}{30} & SADE 13 & 0 & $30 \mathrm{E}-06$ & $.02 \mathrm{E}-05$ & $1.16 \mathrm{E}-05$ & $1.71 \mathrm{E}-05$ & $3.49 \mathrm{E}-06$ & $6.85 \mathrm{E}-07$ & $-1.83 \mathrm{E}-05$ \\
\hline & $\mathrm{ABC}$ 3] & $-9.80 \mathrm{E}-06$ & & $\begin{array}{l}3.04 \mathrm{E}-05 \\
3.05\end{array}$ & $1.83 \mathrm{E}-06$ & $7.26 \mathrm{E}-06$ & $\begin{array}{l}-6.31 \mathrm{E}-06 \\
-6.450\end{array}$ & $\begin{array}{l}-9.11 \mathrm{E}-06 \\
-\end{array}$ & $\begin{array}{l}-1.00 \mathrm{E}-05 \\
-2.81 \mathrm{E}-05\end{array}$ \\
\hline & PSOGSA 54] & $-4.02 \mathrm{E}-05$ & $-3.04 \mathrm{E}-05$ & & $-2.85 \mathrm{E}-05$ & $-2.31 \mathrm{E}-05$ & $-3.67 \mathrm{E}-05$ & $-3.95 \mathrm{E}-05$ & $-5.85 \mathrm{E}-05$ \\
\hline & TLBO 55 & $-1.16 \mathrm{E}-05$ & $-1.83 \mathrm{E}-06$ & $2.85 \mathrm{E}-05$ & 0 & $5.44 \mathrm{E}-06$ & $-8.13 \mathrm{E}-06$ & $-1.09 \mathrm{E}-05$ & $-3.00 \mathrm{E}-05$ \\
\hline & WOA 2 & $-1.71 \mathrm{E}-05$ & $-7.26 \mathrm{E}-06$ & $2.31 \mathrm{E}-05$ & $-5.44 \mathrm{E}-06$ & 0 & $-1.36 \mathrm{E}-05$ & $-1.64 \mathrm{E}-05$ & $-3.54 \mathrm{E}-05$ \\
\hline & & $-3.49 \mathrm{E}-06$ & $6.31 \mathrm{E}-06$ & $3.67 \mathrm{E}-05$ & $8.13 \mathrm{E}-06$ & $1.36 \mathrm{E}-05$ & & $\begin{array}{l}-1.04 \mathrm{E}-06 \\
-2.80\end{array}$ & $-2.18 \mathrm{E}-05$ \\
\hline & HGSA & $-6.85 \mathrm{E}-07$ & $9.11 \mathrm{E}-06$ & & $99 \mathrm{E}-05$ & E-05 & $2.81 \mathrm{E}-06$ & & $-1.90 \mathrm{E}-05$ \\
\hline & $\mathrm{AC}$ & $1.83 \mathrm{E}-05$ & $2.81 \mathrm{E}-05$ & $5.85 \mathrm{E}-05$ & $3.00 \mathrm{E}-05$ & $3.54 \mathrm{E}-05$ & $2.18 \mathrm{E}-05$ & $1.90 \mathrm{E}-05$ & 0 \\
\hline \multirow{8}{*}{50} & $\mathrm{ADE}$ 13] & 0 & & & & & & & \\
\hline & & $-7.59 \mathrm{E}-05$ & & $-1.52 \mathrm{E}-05$ & $\mathrm{E}-05$ & $\mathrm{E}-06$ & $\mathrm{E}-05$ & $\mathrm{E}-05$ & $\begin{array}{ll}0 \mathrm{E}-05 \\
0\end{array}$ \\
\hline & PSOGSA 54] & $-6.07 \mathrm{E}-05$ & $1.52 \mathrm{E}-05$ & 0 & $-7.55 \mathrm{E}-06$ & $7.85 \mathrm{E}-06$ & $-2.09 \mathrm{E}-05$ & $-4.57 \mathrm{E}-05$ & $-7.88 \mathrm{E}-05$ \\
\hline & TLBO 55 & $-5.32 \mathrm{E}-05$ & $2.28 \mathrm{E}-05$ & $7.55 \mathrm{E}-06$ & & $1.54 \mathrm{E}-05$ & $-1.34 \mathrm{E}-05$ & $-3.81 \mathrm{E}-05$ & $-7.13 \mathrm{E}-05$ \\
\hline & 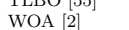 & $\begin{array}{l}-3.32 \mathrm{E}-05 \\
-6.86 \mathrm{E}-05\end{array}$ & $\begin{array}{l}2.28 \mathrm{E}-05 \\
7.39 \mathrm{E}-06\end{array}$ & $\begin{array}{l}\text {-.50E-00 } \\
-7.85 \mathrm{E}-06\end{array}$ & $-1.54 \mathrm{E}-05$ & $\begin{array}{l}1.54 \mathrm{E}-05 \\
0\end{array}$ & $\begin{array}{l}-1.34 \mathrm{E}-03 \\
-2.88 \mathrm{E}-05\end{array}$ & $\begin{array}{l}\begin{array}{l}-3.81 \mathrm{E}-00 \\
-5.35 \mathrm{E}-05\end{array} \\
-\end{array}$ & $\begin{array}{l}-7.13 \mathrm{E}-05 \\
-8.67 \mathrm{E}-05\end{array}$ \\
\hline & & $-3.98 \mathrm{E}-05$ & 3.62E-05 & $2.09 \mathrm{E}-05$ & $1.34 \mathrm{E}-05$ & 2.88 & 0 & $-2.47 \mathrm{E}-05$ & $-5.79 \mathrm{E}-05$ \\
\hline & HGSA $\frac{30}{58}$ & $\begin{array}{l}-0.90 \mathrm{D}-0 \mathrm{O} \\
-1.50 \mathrm{E}-05\end{array}$ & $\begin{array}{l}5.02 \mathrm{E}-05 \\
6.09 \mathrm{E}-05\end{array}$ & & $\begin{array}{l}1.54 \mathrm{~L}-05 \\
3.81 \mathrm{E}-05\end{array}$ & $\begin{array}{l}2.00 \mathrm{E}-05 \\
5.35 \mathrm{E}-05\end{array}$ & $2.47 \mathrm{E}-05$ & $\begin{array}{l}-2.4 / \mathrm{L}-00 \\
0\end{array}$ & $\begin{array}{l}-3.19 \mathrm{E}-03 \\
-3.31 \mathrm{E}-05\end{array}$ \\
\hline & ACVO & $1.81 \mathrm{E}-05$ & $9.40 \mathrm{E}-05$ & $7.88 \mathrm{E}-05$ & 7.13E-05 & $8.67 \mathrm{E}-05$ & $5.79 \mathrm{E}-05$ & $3.31 \mathrm{E}-05$ & \\
\hline
\end{tabular}

the best performing algorithm. ACVO obtains low error rates compared with other algorithms.

Figure 8 represents the convergence behavior of comparison algorithms on test functions $f_{4}, f_{10}, f_{22}$, and $f_{28}$ as representatives from four groups of unimodal, multimodal, hybrid and composite functions. Fig 7 represents the $3 \mathrm{D}$ plot of these functions. As shown in Fig. 8, on $f_{4}$ function, the ACVO and SADE algorithms outperformed counterparts in terms of average bestso-far solution and convergence speed. On $f_{10}$, ACVO, SADE, and HGSA obtained similar performance; however, the ACVO algorithm is a little better. The ACVO outperformed other ones on $f_{22}$ function. The ACVO, SADE, and $\mathrm{HHO}$ algorithms performed better than others on $f_{28}$ function. Overall, ACVO shows a steady convergence behavior, matching or exceeding the best results obtained by other algorithms. It is not trapped in local optima due to its efficient exploration and exploitation of solution space.

Fig 9 shows the distribution of solutions obtained by comparison algorithms on $f_{4}, f_{10}, f_{22}$, and $f_{28}$ functions with 10,30 and 50 dimensions. From Fig 9 (c), (f), (i), and (l), we observe that ACVO obtains the best solutions with minimum deviation from the global solution. Other algorithms generate solutions with larger distribution due to their inconsistent convergence behavior. This justifies that the ACVO is an efficient method to optimize high dimension problems compared with other algorithms. In Fig 9 (a), (b), (d), and (e), the SADE algorithm obtains the best results indicating that it an efficient method to optimize low and medium scale unimodal and multimodal problems. The HGSA obtains the best results on medium scale hybrid and composite functions $f_{22}$, and $f_{28}$. This is shown in Fig $9(\mathrm{~h})$ and $(\mathrm{k})$. For 30 dimension functions, ACVO obtains moderate results; however, its performance is close to HGSA and SADE algorithms. Except for function $f_{10}$, ACVO finds the best solutions on 10 dimension functions compared with other algo- 


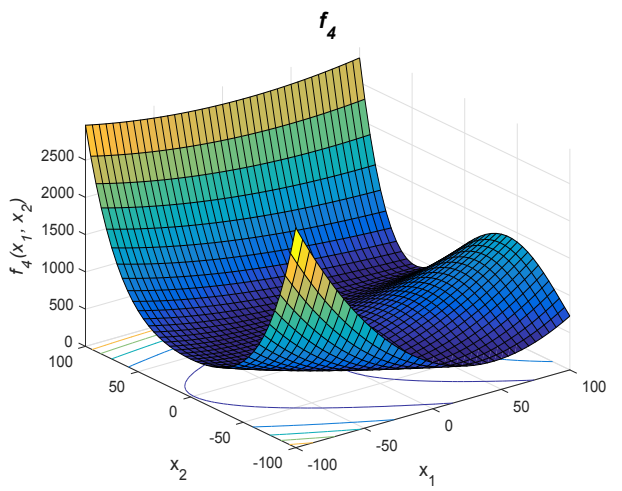

(a)

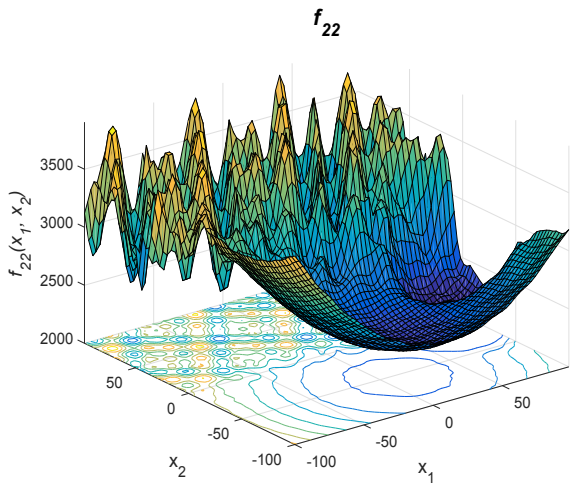

(c)

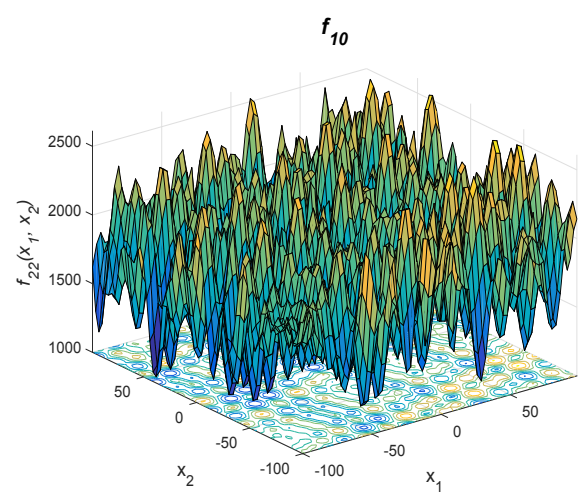

(b)

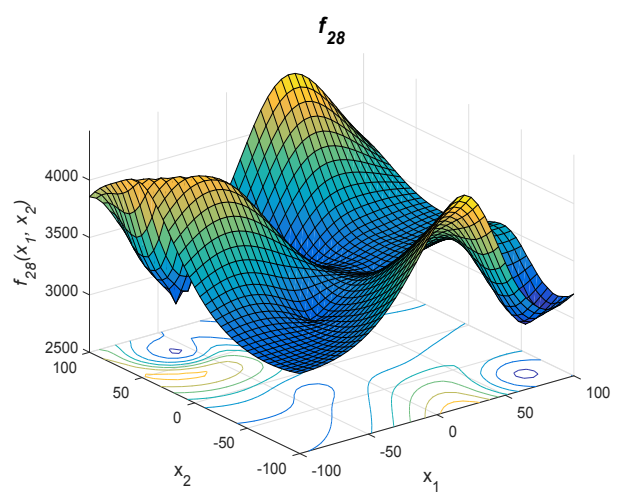

(d)

Fig. 7: Plots of $f_{4}, f_{10}, f_{22}$ and $f_{28}$ test problems

rithms. This indicates that ACVO is a powerful method in optimizing low scale functions. Overall, we can conclude that the ACVO algorithm is an efficient method for solving problems with different dimensions. It is important to note that the algorithms should be tested on a variety of functions to comment more confidently on their performance in finding optimal solutions.

\subsection{ACVO for engineering problems}

To investigate the performance of ACVO in solving engineering applications, it is evaluated on four real-world engineering problems. These problems are drawn from CEC2011 competition [61, and include the frequency-modulated sound waves (FMSW), static economic load dispatch (SELD), transmission network expansion planning (TNEP), and spread spectrum radar poly phase 


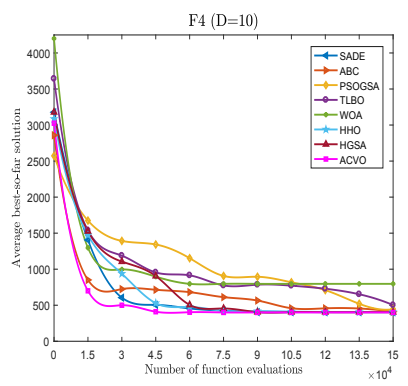

(a)

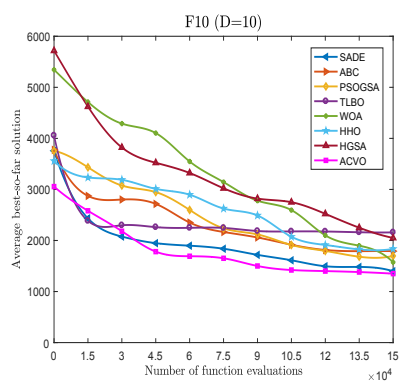

(d)

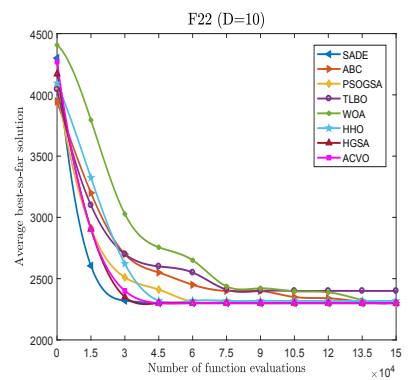

(g)

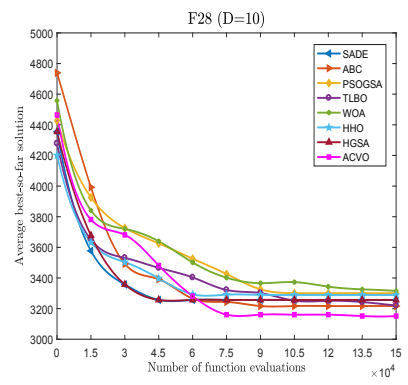

(j)

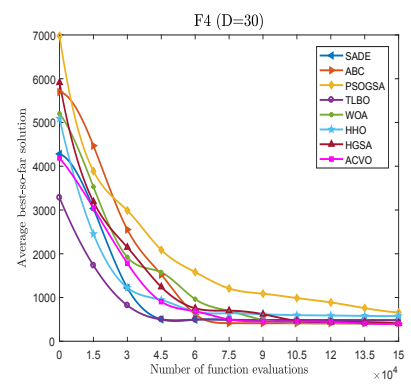

(b)

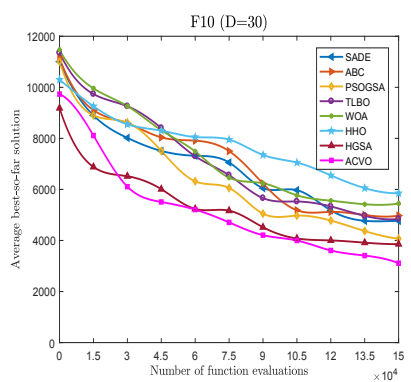

(e)

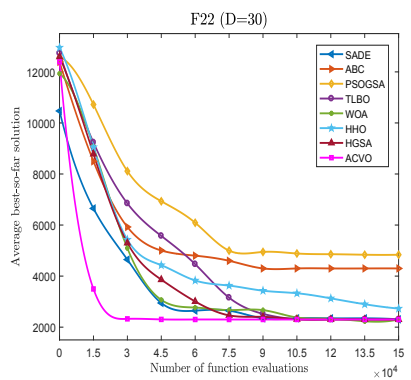

(h)

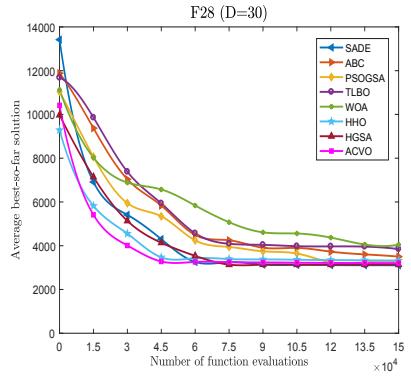

$(\mathrm{k})$

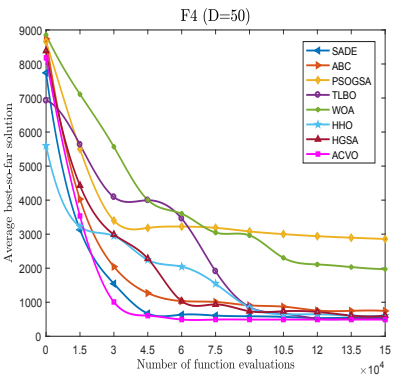

(c)

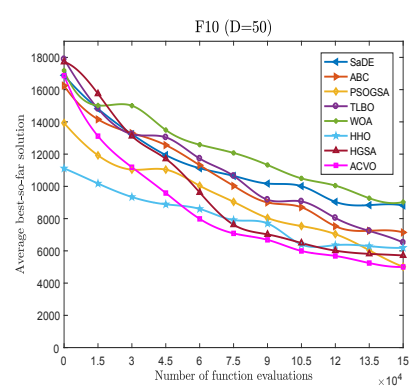

(f)

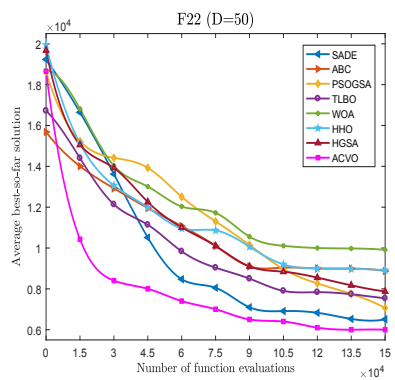

(i)

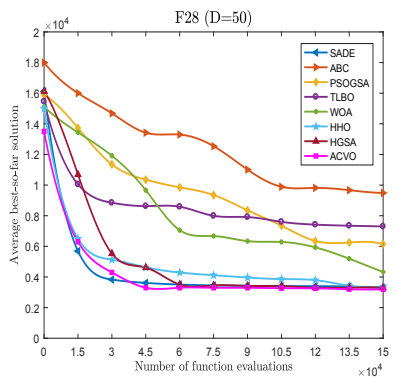

(l)

Fig. 8: Convergence plots of ACVO and counterpart algorithms on $f_{4}, f_{10}, f_{22}$ and $f_{28}$ test functions with 10,30 and 50 dimensions 


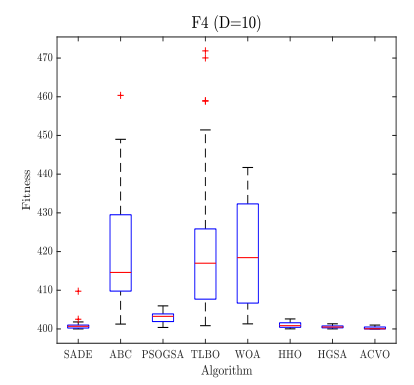

(a)

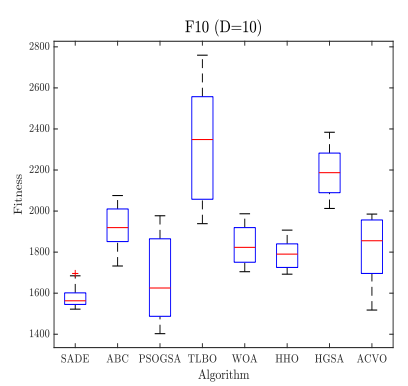

(d)

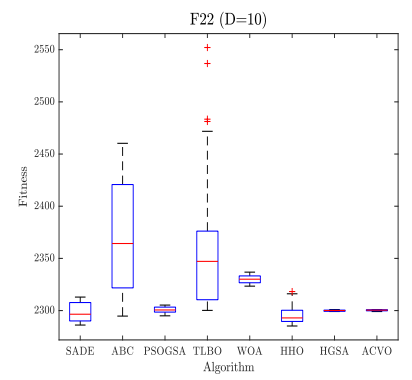

(g)

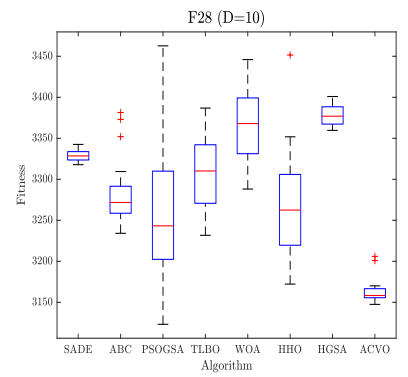

(j)

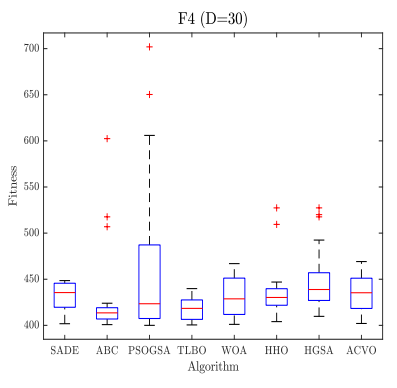

(b)

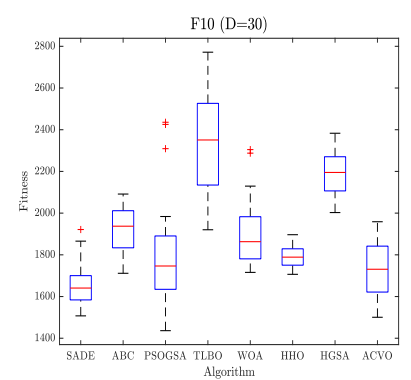

(e)

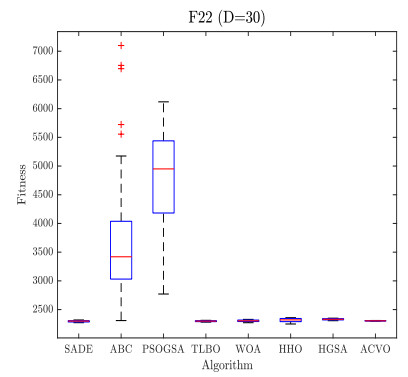

(h)

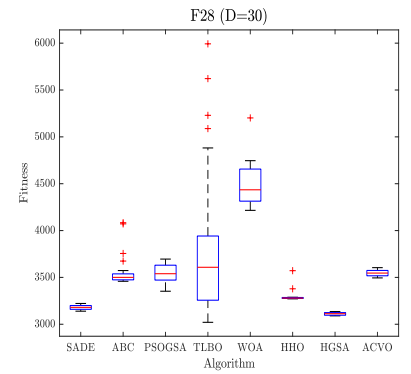

(k)

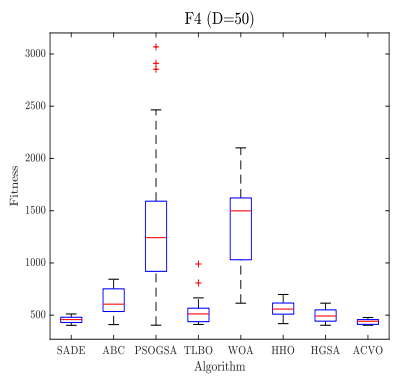

(c)

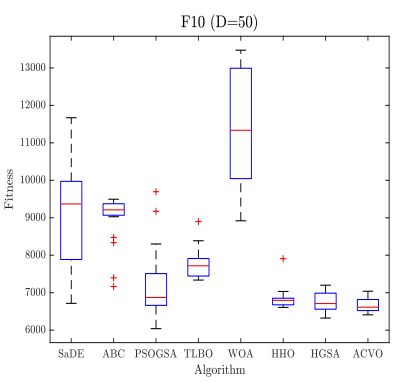

(f)

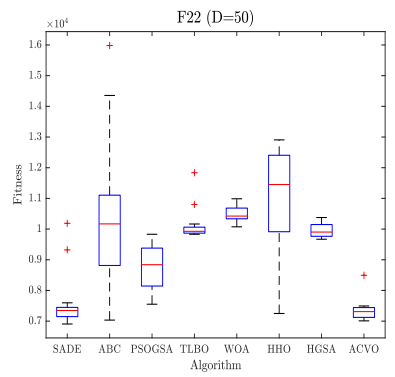

(i)

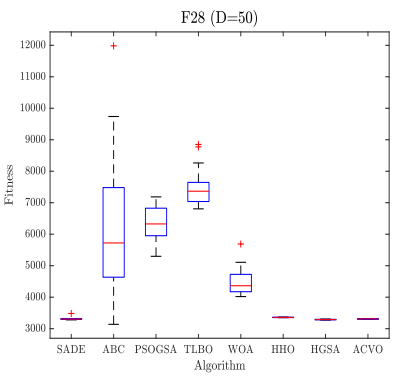

(1)

Fig. 9: The box-and-whisker plots of solutions reported by ACVO and counterpart algorithms on $f_{4}, f_{10}, f_{22}$ and $f_{28}$ test functions with 10,30 and 50 dimensions 
code design (SSRPCD). The characteristics of these problems are summarized in Table 11.

Table 11: Characteristics of four engineering problems

\begin{tabular}{llll}
\hline Problem & Dimension & Constraints & Bounds \\
\hline FMSW & 6 & Bound constrained & {$[-6.4,6.35]$} \\
SSRPCD & 20 & Bound constrained & {$[0,2 \pi]$} \\
TNEP & 7 & Equality and inequality constraints & {$[0,15]$} \\
SELD & \multirow{2}{*}{13} & Inequality constraints & {$[0,680 ; 0,360 ; 0,360 ; 60,180 ; 60,180 ; 60,180 ; 60,180 ;$} \\
\hline
\end{tabular}

\subsubsection{Frequency-modulated sound waves (FMSW)}

The objective of FMSW is to estimate a sound that has the minimum difference with a target sound. FMSW is a multimodal problem with six dimensions that need to be optimized to minimize the difference between the target sound and the estimated sound. The mathematical formulation and constraints of FMSW is formulated as follows 61 :

$$
\begin{aligned}
& \operatorname{minimize} f(\vec{X})=\sum_{t=0}^{100}\left(y(t)-y_{0}(t)\right)^{2} \\
& \text { where } \\
& y_{t}(t)=a_{1} \cdot \sin \left(\omega_{1} \cdot t \cdot \theta+a_{2} \cdot \sin \left(\omega_{2} \cdot t \cdot \theta+a_{3} \cdot \sin \left(\omega_{3} \cdot t \cdot \theta\right)\right)\right) \\
& y_{g}(t)=1 \cdot \sin (5 \cdot t \cdot \theta+1 \cdot 5 \cdot \sin (4.8 \cdot t \cdot \theta+2 \cdot \sin (4.9 \cdot t \cdot \theta)))
\end{aligned}
$$

where $\theta=2 \pi / 100, y_{t}$ is the target sound, and $y_{g}$ is the generated sound by the algorithm.

\subsubsection{Spread spectrum radar polyphase code design (SSRPCD)}

The objective of SSRPCD is to create a radar system using the polyphase codes 58. SSRPCD is a nonlinear problem with many local optima. It falls in the category of continuous min-max global optimization problems, and defined as follows 61]:

$$
\begin{aligned}
& \min _{x \in X} f(x)=\max \left\{\phi_{1}(x), \ldots, \phi_{2 m}(x)\right\} \\
& X=\left\{\left(x_{1}, \ldots, x_{n}\right) \in R^{n} \mid 0 \leq x_{j} \leq 2 \pi, j=1,2, \ldots, n\right\} \\
& \text { subject to } \\
& \phi_{2 i-1}(x)=\sum_{j=i}^{n} \cos \left(\sum_{k=|2 i-j-1|+1}^{j} x_{k}\right), \quad i=1, \ldots, n \\
& \phi_{2 i}(x)=0.5+\sum_{j=i+1}^{n} \cos \left(\sum_{k=|2 i-j|+1}^{j} x_{k}\right), \quad i=1, \ldots, n-1 \\
& \phi_{m+i}(x)=-\phi_{i}(x), \quad i=1, \ldots, m
\end{aligned}
$$

where $n$ is the number of variables and $m=2 n-1$. 


\subsubsection{Transmission network expansion planning (TNEP)}

An optimal design of TNEP is essential for planning the power systems efficiently and economically. The objective of the TNEP is to cope with the problem of finding a set of transmission lines that must be built in a way that no overloads are generated during the planning and achieve the minimum cost of the expansion plan. The TNEP without security constraints is formulated as follows 61]:

$$
\begin{aligned}
& \operatorname{minimize} f=\sum_{l \in \Omega} c_{l} n_{l}+W_{1} \sum_{o l}\left(a b s\left(f_{l}\right)-\bar{f}_{l}\right)+W_{2}\left(n_{l}-\bar{n}_{l}\right) \\
& \text { subject to } \\
& \quad S f+g=d \\
& \quad f_{l}-\gamma_{l}\left(n_{l}^{0}+n_{l}\right)\left(\Delta \theta_{l}\right)=0, \text { for } l \in 1,2, \ldots n l \\
& \left|f_{l}\right| \leq\left(n_{l}^{0}+n_{l}\right) \bar{f}_{l}, \text { for } l \in 1,2, \ldots n l \\
& 0 \leq n_{l} \leq \bar{n}_{l}
\end{aligned}
$$

$n l$ : total number of lines in the circuit

$\Omega$ : set of all right-of-ways

$\bar{n}_{l}$ : the maximum number of circuits that can be added in $l$ th right-of-way $\bar{f}_{l}$ : the maximum allowed real power flow in the circuit in $l$ th right-of-way $f_{l}$ : total real power flow by the circuit in $l$ th right-of-way $o l:$ the set of overloaded lines

$\Delta \theta_{l}$ : phase angle difference in the $l$ th right-of-way

$n_{l}^{0}$ : the number of circuits in the base case

$n_{l}$ : the number of circuits added in $l$ th right-of-way

$c_{l}$ : cost of line added in the $l$ th right-of-way

$S$ : branch-node incidence transposed matrix of the power system

$f$ : the vector with elements $f_{l}$

$\gamma_{l}$ : susceptance of the circuit that can be added to $l$ th right-of-way

\subsubsection{Static economic load dispatch (SELD)}

SELD aims to minimize the fuel cost of generating units through finding the optimal thermal generation schedule provided that four constraints are satisfied. The constraints are prohibited operating zones, generator operation, ramp rate limits, and load demand. SELD is a non-differentiable, complex, and nonlinear problem with multiple local minimums. This problem mathematically is expressed as follows 61: 
minimize $f=\sum_{i=1}^{N_{G}} a_{i} P_{i}^{2}+b_{i} P_{i}+c_{i}$

subject to

$$
\begin{aligned}
& \sum_{i=1}^{N_{G}} P_{i}=P_{D}+P_{L} \\
& P_{i}^{\min } \leq P_{i} \leq P_{i}^{\max } \\
& \max \left(P_{i}^{\min }, U R_{i}-P\right) \leq P_{i} \leq \min \left(P_{i}^{\max }, P_{i}^{t-1}-D R_{i}\right) \\
& P_{i} \leq \breve{P}^{p z} \text { and } \mathrm{P}_{i} \geq \stackrel{P}{P}
\end{aligned}
$$

Table 12 summarizes the best, mean, worst, and standard deviation of objective function values reported by ACVO and counterparts over 30 independent runs. In simulations, the algorithms independently execute 30 times, and the statistical results are reported. At each run, the initial population is formed using uniform random initialization within the predetermined search boundary of each test problem. In terms of best values, the ACVO performed better or had a similar performance to other algorithms in four problems. The mean and $s t d$ values reported by ACVO, one can conclude that it has a steady behavior in finding optimal solutions. The worst values found by ACVO are close to the mean values. This issue justifies that the ACVO can avoid local optimum points. The results given in Table 12 show that the ACVO can be

\begin{tabular}{|c|c|c|c|c|c|c|c|c|c|}
\hline Problem & Statistics & SADE 13] & $\mathrm{ABC} \quad 31$ & $\begin{array}{l}\text { PSOGSA } 54] \\
\end{array}$ & TLBO 55] & WOA 2] & HHO 57$]$ & HGSA 58 & ACVO \\
\hline & Best & $0.00 \mathrm{E}+00$ & $5.99 \mathrm{E}-03$ & $0.00 \mathrm{E}+00$ & $0.00 \mathrm{E}+00$ & $6.20 \mathrm{E}-02$ & $7.97 \mathrm{E}-05$ & $3.55 \mathrm{E}-13$ & $0.00 \mathrm{E}+00$ \\
\hline \multirow{4}{*}{ FMSW } & Mean & $1.49 \mathrm{E}+00$ & $2.99 \mathrm{E}+00$ & $3.18 \mathrm{E}+00$ & $2.60 \mathrm{E}+00$ & $2.71 \mathrm{E}+00$ & $2.32 \mathrm{E}+00$ & $2.11 \mathrm{E}+00$ & $1.49 \mathrm{E}+00$ \\
\hline & Std & $88 \mathrm{E}+00$ & $4.51 \mathrm{E}+00$ & $4.73 \mathrm{E}+00$ & $4.87 \mathrm{E}+00$ & $1.80 \mathrm{E}+00$ & $3.15 \mathrm{E}+00$ & $4.05 \mathrm{E}+00$ & $3.88 \mathrm{E}+00$ \\
\hline & Worst & $14 \mathrm{E}+00$ & $35 \mathrm{E}+00$ & & $6.19 \mathrm{E}+00$ & $5.97 \mathrm{E}+00$ & $5.47 \mathrm{E}+00$ & $6.52 \mathrm{E}+00$ & $5.68 \mathrm{E}+00$ \\
\hline & Best & 01 & $32 \mathrm{E}-01$ & & $21 \mathrm{E}-01$ & $6.27 \mathrm{E}-01$ & $5.48 \mathrm{E}-01$ & $5.00 \mathrm{E}-01$ & $5.00 \mathrm{E}-01$ \\
\hline \multirow{4}{*}{ SSRPCD } & & & & & & & & & \\
\hline & & & & & & & & & \\
\hline & Worst & & $\mathrm{E}+00$ & & & & +00 & & +00 \\
\hline & $\mathrm{Bes}$ & & & +02 & & & +02 & +02 & $\mathrm{E}+02$ \\
\hline \multirow{3}{*}{ TNEP } & & & & & & & & $\mathrm{OE}+02$ & +02 \\
\hline & & 0.00 & $1.56 \mathrm{E}+01$ & & & 5.83 & $1.40 \mathrm{E}+00$ & $0.00 E+00$ & $0.00 \mathrm{E}+00$ \\
\hline & Worst & $2.20 \mathrm{~F}$ & $2.35 \mathrm{E}+02$ & & & & $2.22 \mathrm{E}+02$ & $2.20 \mathrm{E}+02$ & $2.20 \mathrm{E}+02$ \\
\hline \multirow[t]{4}{*}{ SELD } & Best & & & & & & & & \\
\hline & & & & & & & & +04 & $\mathrm{E}+04$ \\
\hline & & $3.48 \mathrm{E}+02$ & 2.53E+02 & $1.60 \mathrm{E}+02$ & $3.81 \mathrm{E}+02$ & $2.66 \mathrm{E}+02$ & $3.30 \mathrm{E}+02$ & $1.14 \mathrm{E}+02$ & $3.75 \mathrm{E}+02$ \\
\hline & Worst & $1.98 \mathrm{E}+04$ & $1.99 \mathrm{E}+04$ & $1.96 \mathrm{E}+04$ & $1.97 \mathrm{E}+04$ & $1.98 \mathrm{E}+04$ & $1.92 \mathrm{E}+04$ & $1.94 \mathrm{E}+04$ & $1.95 \mathrm{E}+04$ \\
\hline
\end{tabular}
applied to various practical and engineering problems.

Table 12: Results of ACVO and counterpart algorithms on four real-world engineering problems

\subsection{Computational complexity}

The time complexity of the ACVO depends on three main steps: initialization, fitness calculation and updating of individuals. To be very precise, the the time complexity of each phase in ACVO is computed as follows:

The parameter initialization phase needs the time complexity $O(1)$.

The population initialization phase needs $O(N)$, where $N$ is the population 
size.

Computing the fitness of all individuals costs $O(N)$.

Controlling the boundary of individuals' variables costs $O(n)$.

The time complexity of social distancing phase is $O\left(n^{2}\right)$.

Quarantine phase needs the time complexity $O(|Q|)$, where $|Q|<N$.

Isolation phase is of order $O(|I|)$, where $|I|<N$.

The overall time complexity of ACVO in each generation in the worst case is as follows:

$$
\begin{aligned}
& O(1)+O(N)+O(N)+O(N)+O\left(N^{2}\right)+O(|Q|)+O(|I|)= \\
& O(1)+3 O(N)+O\left(N^{2}\right)+O(|Q|)+O(|I|) \approx O\left(N^{2}\right)
\end{aligned}
$$

Thus, the overall time complexity of ACVO is $O\left(N^{2}\right)$. The time complexity of SADE, ABC, PSOGSA, TLBO, WOA, HHO, and HGSA is $O\left(N^{2}\right)$ in the worst case. The time complexity of ACVO is the same as its counterparts. This shows that the ACVO is computationally efficient in comparison with other algorithms.

\section{Conclusion}

In this paper, a novel anti-coronavirus optimization (ACVO) algorithm is introduced to solve single-objective optimization problems. This algorithm simulates the protocols recommended by the world health organization to prevent the spreading of coronavirus. It consists of three main operators including social distancing, quarantine, and isolation. These operators hopefully guide the individuals in the population to converge to the global optimum point in solution space. ACVO is relatively easy to implement and customize for various real-world applications. The effectiveness of the proposed algorithm is compared with several state-of-the-art methods on a set of 28 test functions, which covers a wide variety of different problems. The results demonstrate that ACVO obtains outstanding performance in solving single-objective optimization problems. There remain several works to further improve the performance of ACVO. New operators such as vaccination can be embedded in the algorithm to enhance its search power. A multi-objective version of the algorithm should be investigated for solving problems with multiple objectives. The parameters of the algorithm need to be further analyzed to be tuned with optimal values. The algorithm should be applied to various engineering problems to assess its disadvantages and potentials.

\section{Declarations}

- Funding: There is no funding information.

- Conflict of Interest: H. Emami declare that he has no conflict of interest.

- Availability of data and material: There is no data for distribution. 
- Code availability: The source code is submitted as a electronic supplementary material.

- Ethical approval: This article does not contain any studies with human participants or animals performed by any of the authors.

- Author contributions: This paper presents a new swarm intelligence method, namely anti coronavirus optimization algorithm. This algorithm obtains better performance compared with other optimization algorithms.

\section{References}

1. J. Krause and J. Cordeiro, "A survey of swarm algorithms applied to discrete optimization problems," In: Swarm Intelligence and Bio-Inspired Computation," Elsevier, pp. 169-191, 2013.

2. S. Mirjalili and A. Lewis, "The whale optimization algorithm," Adv. Eng. Softw., vol. 95, pp. 51-67, 2016.

3. D. Karaboga and B. Basturk, "A powerful and efficient algorithm for numerical function optimization: Artificial bee colony (ABC) algorithm," J. Glob. Optim., vol. 39, no. 3, pp. 459-471, 2007.

4. H. Emami and F. Derakhshan, "Election algorithm: a new socio-politically inspired strategy," AI Commun., vol. 28, no. 3, pp. 591-603, 2015.

5. X. Yang and S. Deb, "Cuckoo Search via Levy Flights," in 2009 World Congress on Nature \& Biologically Inspired Computing (NaBIC 2009), 2009, pp. 210-214.

6. M. Abdel-Basset, L. Abdel-Fatah, and A. K. Sangaiah, Metaheuristic Algorithms: A Comprehensive Review. Elsevier Inc., 2018.

7. I. Boussaïd, J. Lepagnot, and P. Siarry, "A survey on optimization metaheuristics," Inf. Sci., vol. 237, pp. 82-117, 2013.

8. R. L. Haupt, S. E. Haupt, and a J. Wiley, Algorithms Practical Genetic Algorithms, Second Edi. A JOHN WILEY \& SONS, INC., PUBLICATION, 2004.

9. R. Storn and K. Price, "Differential Evolution- A Simple and Efficient Heuristic for Global Optimization over Continuous Spaces," J. Glob. Optim., vol. 11, pp. 341-359, 1997.

10. X. Yao, Y. Liu, and G. Lin, "Evolutionary Programming Made Faster," IEEE Trans. Evol. Comput., vol. 3, no. 2, pp. 82-102, 1999.

11. C. Ferreira, "Gene Expression Programming: a New Adaptive Algorithm for Solving Problems," Complex Syst., vol. 13, no. 2, pp. 87-129, 2001.

12. C. Igel, N. Hansen, and S. Roth, "Covariance matrix adaptation for multi-objective optimization.," Evol. Comput., vol. 15, no. 1, pp. 1-28, 2007.

13. A. K. Qin and P. N. Suganthan, "Self-adaptive differential evolution algorithm for numerical optimization," IEEE Trans. Evol. Comput, vol. 1, no. 3, pp. 1785-1791, 2005.

14. P. Taylor, E. Mezura-montes, and C. A. C. Coello, "An empirical study about the usefulness of evolution strategies to solve constrained optimization problems," International Journal of General Systems, vol. 37, no. 4, pp. 37-41, 2008.

15. D. Simon, "Biogeography-Based Optimization," IEEE Trans. Evol. Comput., vol. 12, no. 6 , pp. $702-713,2008$.

16. X. Pan and L. Jiao, "A granular agent evolutionary algorithm for classification," Appl. Soft Comput. J., vol. 11, no. 3, pp. 3093-3105, 2011.

17. H. C. Kuo and C. H. Lin, "Cultural Evolution Algorithm for Global Optimizations and its Applications," J. Appl. Res. Technol., vol. 11, no. 4, pp. 510-522, 2013.

18. P. Civicioglu, "Backtracking Search Optimization Algorithm for numerical optimization problems," Appl. Math. Comput., vol. 219, no. 15, pp. 8121-8144, 2013.

19. M. Y. Cheng and D. Prayogo, "Symbiotic Organisms Search: A new metaheuristic optimization algorithm," Comput. Struct., vol. 139, pp. 98-112, 2014.

20. M. Yamato and A. Fujiwara, "A strawberry optimization algorithm for the multiobjective knapsack problem", Bulletin of networking, computing, systems, and software, vol. 8, no. 2, pp. 129-132, 2019. 
21. M. Ghaemia and M.-R. Feizi-Derakhshi, "Forest Optimization Algorithm," Expert Syst. Appl., vol. 41, no. 15, pp. 6676-6687, 2014.

22. F. Merrikh-Bayat, "The runner-root algorithm: A metaheuristic for solving unimodal and multimodal optimization problems inspired by runners and roots of plants in nature," Appl. Soft Comput. J., vol. 33, pp. 292-303, 2015.

23. J. Kennedy and R. Eberhart, "Particle swarm optimization," Proc. ICNN'95 - Int. Conf. Neural Networks, pp. 1942-1948, 1995.

24. M. Dorigo, M. Birattari, and T. Stutzle, "Ant Colony Optimization," IEEE Comput. Intell. Mag., vol. 1, pp. 28-39, 2006.

25. X. S. Yang, "Firefly algorithms for multimodal optimization," Lect. Notes Comput. Sci. (including Subser. Lect. Notes Artif. Intell. Lect. Notes Bioinformatics), vol. 5792 LNCS, pp. 169-178, 2009.

26. X. S. Yang, "A new metaheuristic Bat-inspired Algorithm," in Nature Inspired Cooperative strategies for Optimization (NICSO 2010), 2010, pp. 65-74.

27. K. M. Passino and T. Ohio, "Bacterial Foraging optimization," vol. 1, pp. 1-16, 2010.

28. R. V. Rao, V. J. Savsani, and D. P. Vakharia, "Teaching-learning-based optimization: A novel method for constrained mechanical design optimization problems," CAD Comput. Aided Des., vol. 43, no. 3, pp. 303-315, 2011.

29. A. H. Gandomia and A. H. Alavi, "Krill herd: A new bio-inspired optimization algorithm," Commun. Nonlinear Sci. Numer. Simul., vol. 17, no. 12, pp. 4831-4845, 2012.

30. A. Kaveh and N. Farhoudi, "A new optimization method: Dolphin echolocation," Adv. Eng. Softw., vol. 59, pp. 53-70, 2013.

31. W. T. Pan, "A new Fruit Fly Optimization Algorithm: Taking the financial distress model as an example," Knowledge-Based Syst., vol. 26, pp. 69-74, 2012.

32. S. Mirjalili, S. Mohammad, and A. Lewis, "Grey Wolf Optimizer," Adv. Eng. Softw., vol. 69 , pp. 46-61, 2014.

33. X. Li, J. Zhang, and M. Yin, "Animal migration optimization: An optimization algorithm inspired by animal migration behavior," Neural Comput. Appl., vol. 24, no. 7-8, pp. 1867-1877, 2014.

34. J. J. Q. Yu and V. O. K. Li, "A Social Spider Algorithm for Global Optimization," Appl. Soft Comput. J., vol. 30, pp. 614-627, 2015.

35. M. A. Eita and M. M. Fahmy, "Group counseling optimization," Appl. Soft Comput. J., vol. 22, pp. 585-604, 2014.

36. M. Yazdani and F. Jolai, "Lion Optimization Algorithm (LOA): A nature-inspired metaheuristic algorithm," J. Comput. Des. Eng., vol. 3, no. 1, pp. 24-36, 2016.

37. S. Saremi, S. Mirjalili, and A. Lewis, "Grasshopper Optimisation Algorithm: Theory and application," Adv. Eng. Softw., vol. 105, pp. 30-47, 2017.

38. S. Mirjalili, A. H. Gandomi, S. Zahra, and S. Saremi, "Salp Swarm Algorithm: A bioinspired optimizer for engineering design problems," Adv. Eng. Softw., vol. 114, pp. 1-29, 2017.

39. Y. C. Liang and J. R. Cuevas Juarez, "A novel metaheuristic for continuous optimization problems: Virus optimization algorithm," Eng. Optim., vol. 48, no. 1, pp. 73-93, 2016.

40. Y. C. Liang and J. R. Cuevas Juarez, "A self-adaptive virus optimization algorithm for continuous optimization problems," Soft Comput., vol. 24, no. 17, pp. 13147-13166, 2020 .

41. H. Mo and L. Xu, "Magnetotactic bacteria optimization algorithm for multimodal optimization," Proc. 2013 IEEE Symp. Swarm Intell. SIS 2013 - 2013 IEEE Symp. Ser. Comput. Intell. SSCI 2013, pp. 240-247, 2013.

42. D. H. Wolpert and W. G. Macready, "No Free Lunch Theorems for Optimization," IEEE Trans. Evol. Comput., vol. 1, no. 1, pp. 67-82, 1997.

43. W. Guan et al., "Clinical characteristics of coronavirus disease 2019 in China," N. Engl. J. Med., vol. 382, no. 18, pp. 1708-1720, 2020.

44. B. F. Maier and D. Brockmann, "Effective containment explains subexponential growth in recent confirmed COVID-19 cases in China," Science (80), vol. 368, no. 6492, pp. $742-746,2020$.

45. J. T. Wu, K. Leung, and G. M. Leung, "Nowcasting and forecasting the potential domestic and international spread of the 2019-nCoV outbreak originating in Wuhan, China: a modelling study," Lancet, vol. 395, no. 10225, pp. 689-697, 2020. 
46. R. M. Anderson, H. Heesterbeek, D. Klinkenberg, and T. D. Hollingsworth, "How will country-based mitigation measures influence the course of the COVID-19 epidemic?," Lancet, vol. 395, no. 10228, pp. 931-934, 2020.

47. Y. Liu, A. A. Gayle, A. Wilder-Smith, and J. Rocklöv, "The reproductive number of COVID-19 is higher compared to SARS coronavirus," J. Travel Med., vol. 27, no. 2, pp. $1-4,2020$.

48. L. Matrajt and T. Leung, "Evaluating the Effectiveness of Social Distancing Interventions to Delay or Flatten the Epidemic Curve of Coronavirus Disease," Emerg. Infect. Dis., vol. 26, no. 8, pp. 1740-1748, 2020.

49. S. Sanche, Y. T. Lin, C. Xu, E. Romero-Severson, N. Hengartner, and R. Ke, "RESEARCH High Contagiousness and Rapid Spread of Severe Acute Respiratory Syndrome Coronavirus 2," Emerg. Infect. Dis., vol. 26, no. 7, pp. 1470-1477, 2020.

50. J. Swanson and A. Jeanes, "Title community: a pragmatic approach," Clin. Focus, vol. 16 , no. 6 , pp. 282-289, 2007

51. M. Ye et al., "Treatment with convalescent plasma for COVID-19 patients in Wuhan, China," J. Med. Virol., pp. 0-1, 2020.

52. R. Li et al., "Substantial undocumented infection facilitates the rapid dissemination of novel coronavirus (SARS-CoV-2)," Science (80-. )., vol. 368, no. 6490, pp. 489-493, 2020.

53. D. Wang et al., "Clinical characteristics of 138 hospitalized patients with 2019 novel coronavirus-infected pneumonia in Wuhan, China," JAMA - J. Am. Med. Assoc., vol. 323, no. 11, pp. 1061-1069, 2020.

54. S. Mirjalili and S. Z. M. Hashim, "A new hybrid PSOGSA algorithm for function optimization," Proc. ICCIA 2010 - 2010 Int. Conf. Comput. Inf. Appl., no. 1, pp. 374-377, 2010.

55. R. V. Rao, V. J. Savsani, and D. P. Vakharia, "Teaching-learning-based optimization: an optimization method for continuous non-linear large scale problems," Inf. Sci., vol. 183, no. 1, pp. 1-15, 2012.

56. M.A. Al-Betar, M.A. Awadallah, I.A. Doush, A.I. Hammouri, M. Mafarja, Z.A. Alyasseri, "Flower pollination algorithm for global optimization", in: International Conference on Unconventional Computing and Natural Computation, Springer, Berlin, 2012 , pp. $240-249$.

57. A. A. Heidari, S. Mirjalili, H. Faris, I. Aljarah, M. Mafarja, and H. Chen, "Harris hawks optimization: algorithm and applications," Futur. Gener. Comput. Syst., vol. 97, pp. 849-872, 2019.

58. Y. Wang, Y. Yu, S. Gao, H. Pan, and G. Yang, "A hierarchical gravitational search algorithm with an effective gravitational constant," Swarm Evol. Comput., vol. 46, no. February, pp. 118-139, 2019.

59. Suganthan P, Ali M, Wu G, Mallipeddi R (2018) "Special session \& competitions on real-parameter single objective optimization," In: Proceedings of the IEEE congress on evolutionary computation (CEC), Rio de Janeiro, Brazil, Rep., Jul 2018.

60. J. Derrac, S. García, D. Molina, and F. Herrera, "A practical tutorial on the use of nonparametric statistical tests as a methodology for comparing evolutionary and swarm intelligence algorithms," Swarm Evol. Comput., vol. 1, no. 1, pp. 3-18, 2011.

61. S. Das and P. N. Suganthan, "Problem definitions and evaluation criteria for CEC 2011 competition on testing evolutionary algorithms on real world optimization problems," Jadavpur University, Nanyang Technological University, Kolkata, 2012. 


\section{Supplementary Files}

This is a list of supplementary files associated with this preprint. Click to download.

- SourceCode.rar 